\title{
EL DERECHO PROCESAL CONSTITUCIONAL EN EXPANSIÓN (CRÓNICA DE UN CRECIMIENTO)
}

\author{
Domingo García Belaunde*
}

\begin{abstract}
Resumen:
El autor realiza un recuento histórico del Derecho Procesal Constitucional, centrando el nacimiento de esta disciplina en la década del cuarenta en Argentina, por obra del procesalista español Niceto Alcalá Zamora (exiliado en ese país), y su desarrollo en México por especial dedicación de Héctor Fix-Zamudio. A partir del momento de su nacimiento, el autor realiza una severa investigación acerca del desarrollo del Derecho Procesal Constitucional en México, América del Sur, Centroamérica y el Caribe; deteniéndose en cada país para presentar su producción bibliográfica y los estudios ahí realizados sobre el tema. Presenta, también el panorama europeo, haciendo especial referencia a Francia, España, Italia y Alemania. Finalmente, concluye el autor, que el Derecho Procesal Constitucional, afronta serios problemas, desde el propio nombre hasta los temas que debe tratar y que son parte de su objeto, sin dejar de pasar por su ubicación o naturaleza.
\end{abstract}

Palabras calves: Derecho Procesal Constitucional, Justicia Constitucional

Abstract:

The author makes a historic account of the Constitutional Procedural Law, settling the birth of this discipline in the forties in Argentina, product of the work by the Spanish procedural expert Niceto Alcalá Zamora (exiled in this country), and its development in Mexico, product of the special dedication of Héctor Fix-Zamudio. From the moment of birth, the author realizes a severe investigation about the development of the Constitutional Procedural Law in Mexico, South America, Central A merica and the Caribbean, stopping at each country to present its bibliographic production and the studies there made on the subject. He also presents the European panorama, making a special reference to France, Spain, Italy and Germany.

Finally, the author concludes that the Constitutional Procedural Law confronts serious problems, from its very name to the subjects it must treat, those which are part of its aim, without disregarding its location or nature.

Key words: Constitutional Procedural Law, Constitutional Justice.

* Profesor Principal de la Pontificia Universidad Católica del Perú. 
Sumario:

1. Preliminar. 2. El caso de México. Las aportaciones de Héctor FixZamudio. 3. A mérica del Sur de habla castellana. 4. Centroamérica y el Caribe. 5. Los inicios en la Argentina. El planteo de Sagüés. 6. Otras contribuciones argentinas. 7. El caso del Brasil. 8. El control constitucional en Francia. 9. España y el Derecho Procesal Constitucional. Nota sobre Portugal. 10. El interesante panorama italiano. 11. La situación de Alemania. La tesis de Häberle. 12. A manera de conclusión.

\section{PRELIMINAR}

Los aspectos relacionados con la defensa de la Constitución ocupan al pensamiento jurídico desde hace décadas. En rigor desde que existe o nace el constitucionalismo moderno afines del siglo XVIII, al compás delas revoluciones norteamericana primero, y francesa, después. En la primera como es sabido, en los debates deFiladelfia, y luego en la divulgación deal to nivel quellevó a cabo The Federalist papers, si bien no hubo ninguna concreción a nivel de la dogmática en aquel momento. Y de influencia en Francia fue el planteo de Si eyés, que tampoco alcanzó éxito. Pero es evidente que la inquietud quedó sembrada, y lo queviene después lo explica perfectamente.

En los Estados Unidos ello se concreta en la magistral creación de Marshall en 1803, sobre la cual existe una literatura inmensa (vid. entre otros, Charles E. Hobson, The Great Chief Justice, University Press of Kansas, 1996) que sin embargo sol o seasienta sobrebases firmes a fines del siglo XIX. En Francia por el contrario, por el prurito de la soberanía del parlamento, se avanzó muy lentamente, forjando lo que se ha denominado "control político" que ocupó todo el siglo XIX y que empieza a tramontar con la Constitución de 1958 (cf. AA.VV. L'ordinamento costituzionale della Quinta Repubblica francese, a cura di DominiqueRousseau, Giappichelli editore, Torino 2000).

En el período de entreguerras se da un intenso debateacadémico, sobretodo en Franciay en el mundo germánico, y en menor medida en España. Lo quelleva a la creación del os únicos tribunales constitucionales del período: el austriaco, el checoslovaco y el español.

Al margen de esto, la América Latina, por influencia de la doctrina y la jurisprudencia norteamericanas, creó desde mediados del siglo XIX medidas protectoras de carácter jurisdiccional en defensa de la jerarquía normativa y de los derechos fundamental es. Y esto produjo una literatura muy extensa en varios 
de nuestros países, que de esta suerte se han adelantado a los europeos en la concreción de estas medidas.

Sin embargo, una cosa es tener legislación adecuada que establezca los pasos que se dan a nivel jurisdiccional para alcanzar un objetivo, y muy otra es que todo eso se sistematice y de origen a una disciplina científica. Para poner un ejemplo, veamosun caso relativamente reciente. Durantedécadas los problemas deorden laboral eran una consecuencia y un entramado de orden civil, y fueasí que varios de nuestros códigos civiles consideraban en la sección dedicada a los contratos al contrato de trabajo, hasta quecon el tiempo, seindependizó este apartado y dio nacimiento al moderno Derecho del Trabajo o Derecho Laboral . Quecomo disci plina es recientey quecomo era de esperarse despertó desdesus inicios gran cantidad de problemas teóricos (como por ejemplo dondeubicarlo, cuáles son sus fuentes, sus al cances, etc.).Pero cuyo contenido, es decir, los problemas laborales, son más quemilenarios.

En el control constitucional-queasí lo llamaremos por comodidad-no sepresentó este problema teórico sino hasta muy tarde. Y esto sucedió cuando ya existíay se encontraba muy desarrollada una legislación de orden procesal para llevar adel anteestos procesos. Que en la A mérica Latina se dan desde fines del siglo diecinuevey en Europa en el último período deentreguerras.

Paralelamente, a fines del siglo XIX y principios del XX, seconcreta el Derecho Procesal como rama autónoma dentro del universo jurídico y se desarrolla en dosámbitos muy concretos: el civil y el penal, quevenían desdeatrás y contaban con una larga tradición. Así, el Derecho Procesal Civil y el Derecho Procesal Penal fueron durante décadas las únicas partes de la doctrina procesal que se tomaron en serio.

Sin embargo, no fueron pocos los procesal istas que se dieron cuenta de que esta situación bifronte del proceso podía ser estrecha y en todo caso insuficiente. Y fue Niceto Alcalá-Zamora y Castillo quien habló desde mediados de los años treinta del siglo XX, de una "legislación procesal constitucional" y más tarde lo redondeó en el título que dio a una colección de ensayos que publicó en su exilio en la Argentina: Ensayos deDerecho Procesal . Civil, Penal y Constitucional, Ed. Revista deJ urisprudencia A rgentina, Buenos Aires 1944. Y con posterioridad repitió el aserto, con mayor amplitud, en una reseña bibliográfica que publicó en la "Revista de Derecho Procesal" (tomo III, 2da parte, 1945) que en Buenos Aires dirigía Hugo A Isina. Y volvió sobre 
lo mismo en un libro clásico que publicó en México, como veremos más adelante.

Esta fecha 1944-1945 puede pues considerarse como de la fundación del "Derecho Procesal Constitucional" debida a un procesalista español, radicado en la A rgentina y queluego reiteró en su exilio mexicano.

La larga estancia de Niceto A Icalá-Zamora en México, queduró más detreinta años, dio sus frutos. Y de ahí nació toda una tendencia a desarrollar el "derecho procesal constitucional" como disciplina independiente pero dentro del Derecho Procesal. Correspondiéndole a Héctor Fix-Zamudio el mérito de haber desarrollado la disciplina y haber fijado sus temas, sus problemas y sus contornos teóricos.

Es pues un hecho innegable que el "derecho procesal constitucional" nació en nuestra América, precisamente en la A rgentina por obra de un procesalista español. Pero sedesarrolló más plenamenteen M éxico, por especial dedicación deHéctor Fix-Zamudio y desu amplio magisterio.

Pero mientras esto sucedía, teníamos dos panoramas distintos. Por un lado un avance vertiginoso y ejemplar en la jurisprudencia y la literatura norteamericanas. Pero todo ello dentro del concepto genérico de "judicial review" que en el fondo es una facultad atribuida a todos los jueces que se limitan a inaplicar normas reñidas con la Constitución, si bien esto por la especial estructura y diseño del common law en su vertiente norteamericana, iba a tener influencia en el futuro. Pero sin crearsenada nuevo. Más bien, estos problemas se anal izan en las respectivas ramas procesales existentes en dicho país, tanto a nivel federal como delos estados, y sobretodo dentro delatemática constitucional (como lo demuestran con exceso los manuales sobrela materia, sea los que tienen un enfoque doctrinario, o los que desarrollan el método de casos).

Muy posterior y en cierto sentido distinto es lo sucedido en el ambienteeuropeo en el periodo de entreguerras. Hubo una corriente favorable a la "jurisdicción constitucional" y sobre todo por el modelo concentrado, que se refleja en los tribunales constitucionales que tienen una vida expansiva a partir de 1945, pero sin queello llevasea desarrollos autónomos decarácter procesal. En Europa, salvo excepciones, el problema teórico y de fundamentos se desconoce o en todo caso no interesa o interesa muy poco. 
Teniendo presente esta realidad y considerando que pese a su juventud el Derecho Procesal Constitucional se ha expandido notablemente, es que he optado por hacer aquí un pequeño recuento, casi notarial, de lo queexistesobre el tema, sin entrar a mayores detalles, sino simplemente para dejar constancia delo queexiste.

Para realizar esta pesquisa he tomado en cuenta los si guientes referentes: a)que se trata deubicar principal mentelibros o monografías queversen expresamente sobre el "derecho procesal constitucional" y también recurrir a artículos de revistas cuando esto hasido necesario para mejor entender una situación; b)que en veces, cuando hay muy poco sobre al gún punto o al gún país, heoptado por hacer una referencia general para dejar anotado por dondevan las inquietudes académicas, c)que por razones obvias, no solo de material existente sino por preferencias académicas, he puesto un mayor peso en el análisis de la producción latinoamericana, que no solo es la nuestra, sino que curiosamente es la más preocupada por el tópico y d)que para hacer un cortenecesario en el tiempo, he considerado como fecha límite para mis investigaciones el mes de diciembre de2006, y por tanto lo quepueda salir después no ha sido considerado.

Finalmente, señalo que lo queaquí se incluyey seda cuenta, probablementeno es todo lo queexiste, pero decididamentees bastantey quizálo más significativo. Y aun así, esto me ha tomado un tiempo considerable, que he empleado en visitar bibliotecas en distintos países y en solicitar la colaboración de muchos colegas y amigos sin los cual es esteensayo no hubiera podid o elaborarse y a los queaquí reitero mi expreso reconocimiento.

Sin ánimo exhaustivo debo mencionar la ayuda, entremuchos otros y haciendo referencia por países a las siguientes personas: G. DeV ergottini, Lucio Pegoraro, Luca M ezzetti, Silvio Gambino,Tania Groppi, Edgar Carpio y César I. Astudillo, para el caso del talia; Louis Favoreu,J oséjulio Fernández Rodríguez y A Ifonso Herrera, para información sobre Francia; Peter Häberle y Joaquín Brage Camazano para A lemania (el primero, además, tuvo la gentileza de hacerme una selección de textos alemanes que luego de hacer traducir he utilizado largamente); Francisco Fernández Segado y Fernando Rey, para España; Héctor Fix-Zamudio, Eduardo Ferrer M ac-Gregor y A níbal QuirogaLeón para M éxico; Jorge Silvero Salgueiro y Sebastián Rodríguez Robles, para Panamá; Rubén Hernández Valle, para Costa Rica; Jorge Mario García Laguardia y Gerardo Prado, para Guatemala; Olivo Rodríguez H uertas para República Dominicana; Allan R. Brewer-Carías y JoséVicente H aro para Venezuela; JoséF. Palomino 
Manchego y Gerardo Eto Cruz para el Perú; J osé A ntonio Rivera Santibáñez, para Bolivia; Francisco Zúñiga, para Chile; N éstor P. Sagüés y Eloy EspinosaSaldaña Barrera, para la Argentina; Eduardo G. Esteva Gallicchio para el Uruguay; Paolo Medina, para el Brasil y Eduardo Lara Hernández y Andry Matilla para Cuba. A lo que debo agregar que muchos autores que aquí se consideran, tuvieron lagentileza de hacermellegar ejemplares de al gunas obras que no tenía o que era muy difícil conseguir (lo cual, creo, es una constanteen toda la producción bibliográfica latinoamericana).

Desuma utilidad, a la quemeremito para mayores precisiones, es la Encuesta sobre Derecho Procesal Constitucional, quehe coordinado con Eloy EspinosaSaldaña B. y queseha publicado simultáneamenteen Lima y en M éxico (Jurista Editores y Editorial Porrúa, 2006).

\section{EL CASO DE MÉXICO. Las aportaciones de Héctor Fix-Zamudio}

Debido ala existencia másquecentenaria del A mparo (creado en la Constitución yucateca en 1841 y confirmado en el ámbito nacional con el Acta de Reformas de 1847) ha existido una frondosa literatura en torno a esteinstituto, dedicado principalmenteal control dela constitucionalidad delas leyes-y posteriormente a la defensa de los derechos fundamentales y otros tópicos-lo que explica el interés que ha despertado en la doctrina.

Así, a fines del siglo XIX hay que destacar la presencia y la obra de Ignacio L.Vallartay posteriormentey ya entrado el siglo XX, la no menos importante de Emilio Rabasa.

Sin embargo, como quiera queel instituto del A mparo fuetomando fuerza, se crearon en las universidades cursos dedicados a su estudio, al margen del curso de Derecho Constitucional propiamente dicho, y eso explica la gran cantidad de ensayos y libros dedicados al tema.

El libro emblemático por décadas y desdelos años de 1940, ha sido el delgnacio Burgoa (cf. El juicio de A mparo, Edit. Porrúa, 4lava edición, M éxico 2005 con reimpresión en 2006) que prácticamente uniformó las bases del centenario instituto mexicano y fueel texto formativo de varias hornadas universitarias. EI ilustremaestro analizaba el A mparo desdeenfoques quevenían del procesalismo español decimonónico, y sin tomar mayormente en cuenta los avances de la doctrina procesal moderna, a la que en cierto sentido se resistía. 
Esto empezó a cambiar lentamente cuando llegó a enseñar en la Universidad Nacional Autónoma de México el gran procesalista español Niceto AlcaláZamora y Castillo, que venía de la Argentina en donde había cumplido una labor encomiable. Y es en México en donde publica su monografía clásica Proceso, autocomposi ción y autodefensa (Imprenta U niversitaria, México 1947, con reimpresiones) y en donde hace referencia, si bien muy de pasada, a una nueva disciplina que denomina "derecho procesal constitucional", como antes lo había hecho en la A rgentina (en 1944 y 1945).

La obra de Alcalá-Zamora no solo fue importante por su producción bibliográfica, sino por la difusión de las nuevas ideas, por la traducción de textos fundamentales y por la formación de nuevas promociones de procesalistas. Entre ellos destacan Héctor Fix-Zamudio, Humberto Briceño Sierra, Cipriano Gómez Lara y Sergio García Ramírez.

Pero el que más se dedicó al tema fue sin lugar a dudas Héctor Fix-Zamudio, quien inicia su andadura académica con su tesis de licenciatura, que publica en tirajecorto y quetitula: La garantíajurisdiccional dela Constitución mexicana (Ensayo de una estructuración procesal del A mparo), Facultad de Derecho de la UNAM, México 1955(pero que defiende en enero de 1956).La tesis tiene la siguienteestructura:

- Cap. I: Planteamiento del problema.

- Cap. II: Situación de la materia en el campo del Derecho Procesal.

- Cap. III: El Derecho Procesal Constitucional.

- Cap.IV: El proceso constitucional.

- Cap. V: Conclusiones.

Lo importante de esta tesis es que es la primera vez que se afronta el problema central de donde y cómo desarrollar el Derecho Procesal Constitucional incluyendo dentro de él al Amparo, que aparece así como una categoría netamente procesal. De esta manera, los estudios iniciales de Fix-Zamudio constituyen un corte con todo lo que existía hasta esa fecha sobre el Amparo, pues en el futuro, si bien lentamente, los estudios irán en la línea de trabajo abierta por él. Y por otro, es la primera vez que se intenta, con detalle, un desarrollo doctrinario sobre lo que es el "derecho procesal constitucional", si bien es cierto que esto fue posible gracias al magisterio de A lcalá-Zamora y Castillo. 
Los capítulos III y IV de esta tesis-de circulación restringida necesariamentese publican al año siguiente en una revista de muy amplia circulación: La Justicia en sus números correspondientes a los meses de enero (núm. 310) y setiembre (núm. 317) de 1956, lo que como era de preverse, fue bien acogido por la comunidad jurídica mexicana. Años más tarde, la totalidad de este texto pionero lo inserta en su libro El juicio deA mparo, Edit.Porrúa, M éxico 1960, pp. 5-70.

Fix-Zamudio continua publicando sobre este y otros temas, de los cuales representa una inflexión importante el cursillo que impartió en 1965 y que publica poco después: Veinticinco años deevolución delajusticia constitucional: 1940-1965, UNAM, M éxico 1968.Esta obra inicia, por así decirlo, una nueva etapa en el pensamiento denuestro autor, pues manteniendo el enfoque procesal, intenta hacer ampliaciones en otros campos jurídicos cercanos a lo procesal y con desarrol los paral el os y dentro de una concepción teórica de mayor al cance, tratando de explicar y tipificar la problemática total anunciada en el título dela obra. Y así lo reitera su ponencia de 1975 titulada: Función del Poder Judicial en los sistemas constitucionales latinoamericanos (publicada en el libro colectivo del mismo nombreeditado por la UN AM y en 1977).

Un replanteo y puesta al día de todo lo anterior lo encontramos en un ensayo que publica años más tarde, en 1999: Introducción al Derecho Procesal Constitucional y quereproduce en foll eto en FUN DAP, Querétaro 2002.

La última contribución de Fix-Zamudio que sintetiza todo lo anterior y que representa su pensamiento final sobre estos temas, lo encontramos en un libro de largo alcance: La defensa de la Constitución en el ordenamiento mexicano, 2da edición, Edit.Porrúa, M éxico 2006, que ha merecido una gran acogida.

Es pertinente señal ar queen el ámbito procesal ha sido muy importantela obra de Cipriano Gómez Lara, autor de una Teoría General del Proceso que ha sido la primera en publicarse en M éxico y quetiene en la actualidad diez ediciones (Oxford, M éxico 2004). También debe considerarse su ensayo La teoría general del proceso y el Derecho Procesal Constitucional publicado en un colectivo sobrela materia a cargo deEduardo Ferrer M ac-Gregor, y al quehago referencia más adelante.

Igualmente en el ámbito procesal y perteneciente a una generación posterior tenemos a J osé OvalleFavela, Teoría General del Proceso, 5ta edición, Oxford, 
México 2003 y que contiene un desarrollo expreso del "derecho procesal constitucional" como una disciplina procesal.

Pero quien hasi do el motor dela disci plina en los últimos años ha sido Eduardo Ferrer Mac-Gregor, no solo por su intensa actividad académica, que incluye publicaciones periódicas y no periódicas, sino por el impulso dado a eventos sobrela disciplina y sobretodo por fomentar el interés delos juristas mexicanos en el tema, así como de sus colegas extranjeros. I niciado con un libro de corte comparativo sobre la acción de A mparo en M éxico y España (que fue su tesis doctoral) fue continuado con otro sobre los tribunales constitucionales en Iberoamérica, acompañado de gran cantidad de ensayos sobre temas afines, que en parte ha compilado en su libro Estudios sobre Derecho Procesal Constitucional (Edit. Porrúa, M éxico 2006).

Pero la obra cumbre que representa todo este esfuerzo es el colectivo por él coordinado que setitula Derecho Procesal Constitucional, editado por primera vez por la Editorial Porrúa en 2001, al cual han seguido otras ediciones quehan culminado en una cuarta en cuatro tomos publicada en el año 2003, a la que hay queagregar una reimpresión en 2006,con el añadido de un apéndice sobre el proyecto de una nueva ley de A mparo, haciendo un total de 4,094 páginas y con la participación de más de cien autores que provienen de los más diversos países. Al margen de esto, Ferrer M ac-Gregor ha publicado un Compendio de Derecho Procesal Constitucional, 3ra edición, Edit.Porrúa, M éxico 2005, que contiene legislación, prontuario y bibliografía y quees desuma utilidad para el abogado practicante.

Adicional mente, Ferrer Mac-Gregor ha dado gran impul so a lo queél denomina con todo acierto como "derecho procesal constitucional local", presente sobre todo en los Estados con estructura federal como es el caso de M éxico, y que también se da en otros países que tienen estructura compuesta (como es la Argentina) pues muchas veces los ordenamientos internos son más avanzados que los del orden nacional, y por eso despiertan la curiosidad delos estudiosos. En esta línea, acaba de publicar conjuntamente con M anuel González Oropeza el colectivo Lajusticia constitucional en las entidades federativas (Edit. Porrúa, M éxico 2006), con un título distinto, que suponemos debe haberse hecho por concesiones editoriales.En paral elo a estas actividades, Ferrer Mac Gregor fundó y puso en marcha la "Biblioteca Porrúa de Derecho Procesal Constitucional", con dieciséis volúmenes hasta la fecha, y que ha dado cabida a un elenco al tamentecalificado detemas y deautores sobrela disciplina, no sol o deM éxico, sino de otros países. 
En las nuevas hornadas hay que destacar los estudios de César I. Astudillo Reyes, Ensayos dejusticia constitucional en cuatro ordenamientos de M éxico: Veracruz, Coahuila, Tlaxcala y Chiapas, UNAM , M éxico 2004 y su artículo La justicia constitucional local en M éxico.Presupuestos, Sistemasy Problemas en "Boletín Mexicano de Derecho Comparado", núm. 115, enero-abril de 2006, quien partedeuna visión más tradicional (apegadaal uso ital iano del término), pero no por ello menos sólida.

PosteriormenteCésar I. Astudillo viajaa España dondeprepara su tesis doctoral quetitula: El Derecho Procesal Constitucional como derecho con especificidad propia para la garantía de la Constitución, que defiende en la Universidad Complutense en 2006, y que no ha sido publicada. En esta tesis, gigantesco esfuerzo por juntar y analizar todas las fuentes posi bles, lo que hace con rigor y demanera exhaustiva, A studillo arriba al nuevo nombre o neol ogismo como gusta repetir, pero sin tomar una decisión sobre la ubicación de la disciplina, a la que le da cierta configuración ecléctica.

Al margen de lo señalado, existen gran cantidad de ensayos, monografías y libros dedicados al Amparo, al control constitucional y a la defensa de la Constitución, muchos con el título clásico de "justicia constitucional" (en especial el muy importante de Carlos A. Morales Paulín y ensayos de Edgar Corzo) o "jurisdicción constitucional" e incluso con el de "derecho procesal constitucional" (Manlio F. Casarin León). O que están dedicados a alta divulgación como el colectivo coordinado por Raymundo Gil Rendón (cf.D erecho Procesal Constitucional, Fundap, Querétaro 2004).

Igualmenteseha traducido y publicado en México, gran cantidad detextos de autores extranjeros quehan investigad o el tema, como es el caso dePeter Häberle, Gustavo Zagrebelsky, Lucio Pegoraro, Giancarlo Rolla y sobre todo los clásicos trabajos de Mauro Cappel letti y desdefecha muy temprana (1961). Y dealgunos autores latinoamericanos que han trabajado sobre lo mismo (como Osvaldo A.Gozzaìni y Domingo García Belaunde).

Tampoco debeolvidarselos frecuentes encuentros, nacionales einternacionales, organizados sobre la disciplina (así, el col oquio internacional organizado por la Universidad Autónoma de Nueva León en setiembre de2004 y cuyas ponencias han sido publicadas bajo la coordinación de Germán Cisneros Farías cf. Derecho Procesal Constitucional, coloquio internacional, Universidad de Nueva León, Monterrey 2004).En este mismo evento secreó el Instituto M exicano deDerecho 
Procesal Constitucional y al año siguiente (2005) en la misma Universidad de Nueva León y en coordinación con el Instituto del nvestigaciones Jurídicas dela UNAM , se efectuó el I Congreso M exicano de Derecho Procesal Constitucional.

Finalmente hay que destacar la presencia de la Revista Iberoamericana de Derecho Procesal Constitucional, la primera en su género, fundada en Puebla en diciembre de 2002 por iniciativa de A níbal Quiroga León, Domingo García Belaúnde, José F. Palomino Manchego y Eduardo Ferrer Mac-Gregor, pero impulsaday dirigida por esteúltimo, cuyo primer número apareció en 2004 en México con el respaldo dela Editorial Porrúa y quecontinua hasta el momento con periodicidad semestral. Y en donde se da cuenta de lo que sucede en la problemática procesal-constitucional en el mundo actual, con especial énfasis en el ámbito latinoamericano. Y que se ha convertido en el referente obligado para los estudiosos del área.

Dentro del campo procesal propiamentedicho, debecontarse con el magisterio y la producción, en parteno publicada, de Gumesindo García M orelos, queen tesis doctoral presentada en la Universidad Complutenseen M adrid en 2005 (y de la que alista publicar la primera parte referida al "derecho procesal constitucional" en la prestigiosa editorial argentina Platense) acepta el Derecho Procesal Constitucional desde una estricta óptica procesal, desarrollándolo en forma adecuada. Con anterioridad había publicado un interesante análisis comparativo de dos instituciones garantistas; cf. El Amparo-H abeas Corpus, ABZ editores, M éxico 1998.

Lo que he señalado es solo lo que puedeconsiderarsecomo principal en lo que serefierea la producción jurídica mexicana decarácter procesal constitucional, pero no agota el estudio de las instituciones de control de constitucionalidad que se da en otros ámbitos y en otras publicaciones. Que comprueba que en México no solo existe una sorprendente actualidad en los estudios, sino que ellos han encontrado amplia acogida en la comunidad jurídica. Que son los frutos que ha dado la obra escrita y no escrita de Héctor Fix-Zamudio que constituye, sin lugar a dudas, el referenteobligado en el ámbito iberoamericano.

\section{AMÉRICA DEL SUR DE HABLA CASTELLANA}

Colombia y Venezuela son los dos países que en la América del Sur tienen un antiguo y bastanteel aborado sistema de control constitucional, que seremonta a mediados del siglo XIX, como ha sido demostrado por los estudiosos (como es 
el caso deJames A. Grant). Y que ha dado origen a una cantidad muy grandede publicaciones sobre diversos temas sobre todo de orden práctico o procesal de tales instrumentos. Pero esto no hal levado a planteos teóricos delargo alcance.

Así en Colombia, por ejemplo, se usa desde temprano el concepto de jurisdicción constitucional (cf. Alfredo A raújo Grau, Jurisdicción constitucional, Talleres Gráficos "Mundo al día", Bogotá 1936) y lo mismo sucede en la manualística. Y esto se refuerza desdela década de los cincuenta del siglo pasado (cf. Álvaro Copete Lizarralde, Lecciones de Derecho Constitucional Colombiano, 2da edición, Edit. Temis, Bogotá 1957, 3ra. edición en 1960; Luis Carlos Sáchica, Nuevo constitucionalismo colombiano, Edit. Temis, Bogotá 1992; Jacobo Pérez Escobar, Derecho Constitucional Colombiano, EditTemis, 6ta edic. Bogotá 2003; Diego Younes M oreno, Derecho Constitucional Colombiano, 6ta edic. Ed. Jurídicas G. I báñez, Bogotá 2005; JaimeVidal Perdomo Derecho Constitucional General einstituciones políticas colombianas, Legis, Bogotá 2005). Colombia tieneuna larga tradición jurídica, muy asentada, que se refleja en una cadena de publicaciones sobre temas constitucional es y procesales, que ha aumentado vertiginosamentea raíz de la creación de la Corte Constitucional en 1991 y numerosos libros dedicados a estudiar su actividad y su numerosa jurisprudencia, en muchos aspectos modélica (cf. Sandra Morelli Rico, La Corte Constitucional: un papel institucional por definir, Edic. Academia Colombiana de Jurisprudencia, Bogotá 2001; A A.VV. Justicia constitucional: el rol dela Corte Constitucional en el Estado contemporáneo, Ricardo Sanín Restrepo, coordinador, Universidad Javeriana- Legis editores, Bogotá 2006).

Sin embargo, los procesalistas no sehan preocupado por el tema, al queignoran o tratan de soslayo sin mayor comprensión (así, Hernando Devis Echandía al estudiar la labor dela CorteConstitucional en su país, dicequeésta desarrolla una suerte dejurisdicción constitucional sui generis, cf. Compendio deDerecho Procesal.Teoría general del proceso, 14ava edición, Editorial ABC, Santafé de Bogotá 1996, tomo I, pág. 100).

Y son más bien los constitucionalistas los que han abordado el campo. Así, Ernesto Rey Cantor es el primero que se preocupa del nuevo concepto en una sintética pero bien informada Introducción al Derecho Procesal Constitucional (Univ. Libre, Seccional Cali, 1994) en donde señala que el Derecho Procesal Constitucional es el que regula las actuaciones y procesos constitucionales (pág. 29) y acepta la distinción entre el "derecho procesal constitucional" y el 
"derecho constitucional procesal", siguiendo así el planteo de H. Fix-Zamudio. Posteriormente el mismo autor publica su Derecho Procesal Constitucional, Derecho Constitucional Procesal y Derechos Humanos Procesales, Edic. Ciencia y Derecho, Bogotá 2001, en donde reitera y amplia lo expuesto anteriormente. La obra de Rey Cantor acompañada por su labor docente, no ha encontrada prácticamenteeco en Colombia, en dondeen solitario defiendela existencia de esta nueva disciplina.

Con posterioridad, Javier Henao Hidrón ha publicado una obra con el nombre Derecho procesal constitucional (Edit. Temis, Bogotá 2003,2da edición 2006) que es la nueva versión de una obra anterior en la que utilizaba el título de "jurisdicción constitucional" y que tuvo muchas ediciones. En esta nueva publicación estudia y analiza el carácter procesal de los instrumentos e instituciones que existen en Colombia, pero evita todo anál isis sobre lo que el título anuncia.

De interés es el libro colectivo Nuevas tendencias del Derecho procesal constitucional y legal (Universidad deM edellín, M edellín 2005) quecontieneel ensayo de Diana María Ramírez Carvajal ("Hacia la construcción de un derecho procesal constitucional para Colombia") con un enfoque netamente procesal, pero que aparece desconectado y un poco al margen de la bibliografía que existe en el área, e incluso dela desu propio país.

Mención especial merece la extensa como solvente obra de Eduardo Rozo Acuña, instalado hace años en el ambiente universitario italiano y actualmente Profesor Ordinario de la Universidad deUrbino, que ha dedicado gran parte de su actividad como docente y publicista a dar a conocer la problemática constitucional dela A mérica Latina, sin escatimar juicios y enfoques propios y queincluyeel análisis y la difusión del pensamiento político-constitucional deBolívar. Entresu producción recientey en relación con lo nuestro, ledebemos un libro de largo aliento: Le garanzie costituzionali nel diritto pubblico dell 'A merica Latina,G. Giappichelli editore, Torino 2006(hay traducción castellana, con ligeras variantes). El autor no ingresa al tema conceptual que nos ocupa-pues no es eseel sentido desu obra-sino queacepta como sinónimas las expresiones de Justicia constitucional, Jurisdicción constitucional y Derecho Procesal Constitucional (pág. 21-22 de la edición italiana). El libro por lo demás, representa un esfuerzo notable al juntar información dispersa sobre los procesos constitucionales en nuestro continente, que se presentan en forma sistemática y con enfoques y planteos originales, que lo hacen de 
uso obligado no solo para el estudioso extranjero, sino también para el latinoamericano.

En Venezuela contamos con el texto pionero de JoséGuillermo A ndueza A cuña titulado La Jurisdicción Constitucional en el Derecho Venezolano y quepublica en Caracas en 1955 (con reimpresión en 1974). Y lo mismo hace posteriormente Orlando Tovar (cf. La jurisdicción constitucional, Caracas 1983). A partir dela década delos setenta hay quemencionar la influyentey sólida obra deH umberto J. La Roche, que quizá es el primero que usa el concepto "derecho procesal constitucional" en 1977 en la ponencia que presenta en Sochagota en noviembre de ese año, y dentro de un evento dedicado a la jurisdicción constitucional en Iberoamérica (cf. La jurisdicción constitucional en Venezuela y la nueva Ley Orgánica de la Corte Suprema de Justicia en AA.VV. "La jurisdicción constitucional en Iberoamérica", Univ. Externado de Colombia, Bogotá 1984). Pero el tema, aún cuando vuelve sobre él más adelante (cf. Instituciones constitucionales del Estado venezolano, Maracaibo 1984, pp. 288-293) no es objeto demayores desarrol los. Y más bien en los últimos años seha afirmado la tendencia a usar el rubro de "justicia constitucional" aún cuando no se han hecho demasiadas precisiones (así, por ejemplo, Jesús M aría Casal H., autor de importantes textos en la disciplina, utiliza ambos, justicia y jurisdicción constitucional es como sinónimos. Y lo mismo podríamos decir deJ oséVicente Haro, que ha dedicado importantes textos al tema quenos ocupa).

Pero el que más ha persistido en el tema y que además ha intentado darle un sustento teórico serio, ha sido Allan R.Brewer-Carías, desde principios de la década de los ochenta, en diversas publicaciones en donde ha desarrollado temas tanto de Derecho Constitucional como de Derecho Administrativo, muchos de ellos traducidos al inglés y al francés.

Sus grandes aportaciones, sin embargo, seencuentran en cierto sentido reunidas en su monumental Instituciones Políticas y Constitucionales, Universidad Católica del Táchira y Editorial Jurídica Venezolana, 3ra edición, 7 tomos, Caracas-San Cristóbal 1996-1998, cuyo tomo VI está dedicado a "La justicia constitucional" y que es una síntesis admirable de toda la problemática, tanto de la supremacía constitucional como de los medios para hacerla valer, y en dondese extiende largamente sobretemas defundamentos.

Al ser derogada la Constitución de 1961, sobre la cual se asentaba el Tratado antes referido, Brewer-Carías emprendió un análisis del nuevo texto 
constitucional en forma aguda y solventada pues fue miembro dela A samblea Constituyentequela redactó, si bien por partedela oposición, y sus puntos de vista Ios condensa en La Constitución de 1999 (Derecho Constitucional Venezolano) Editorial Jurídica Venezolana, 4ta edición, 2 tomos, Caracas 2004) y finalmenteen su foll leto El sistema dejusticia constitucional en la Constitución de 1999,Editorial Jurídica Venezolana, Caracas 2000. Su autor no se muestra partidario del "derecho procesal constitucional", ni tampoco de conceder un carácter procesal a estos instrumentos, sino más bien piensa en una defensa constitucional desde adentro, evitando así toda referencia "procedimental", declarando que por "justicia constitucional" entiende la totalidad del universo de garantías y controles de la Constitución, y por "jurisdicción constitucional" el órgano especifico, Corte Suprema o Tribunal Constitucional, que tiene competencias para ello. Setrata de un planteo muy elaborado, que denota una clara influencia francesa, que como sabemos se ha extendido bastante, sobre todo en Italia. En otras palabras, la "justicia constitucional" es un concepto material, mientras que la "jurisdicción constitucional" es un concepto orgánico; la primera se refiere a una materia determinada (control judicial de la constitucionalidad de las leyes y demás actos estatales) mientras quela segunda tiendea identificar a un enteu órgano especializado en esto, como es el caso del Poder Judicial en Venezuela (cit. pp. 12-14).

Continuador de la obra de Brewer-Carías es, en cierto sentido, Carlos A yala Corao, autor devarios trabajos sobreel tema desdela década del 80 , y en donde utiliza preferentemente el concepto de "jurisdicción constitucional", aun cuando marginalmente se ha referido al "derecho procesal constitucional" (así en el prólogo al libro de Gustavo J. Linares Benzo, El proceso de A mparo en Venezuela, Edit. Jurídica Venezolana, Caracas 1993).

La aprobación de la nueva Constitución en 1999 ha promovido gran cantidad de estudios, sin que se hayan hecho avances en este tópico.

En Ecuador, no obstante haberse ensayado la creación de órganos de control constitucional desde 1945, no encontramos nada en relación con el tema, pues se utiliza preferentemente el término "justicia constitucional" (cf. Hernán Salgado Pesantes, M anual de Justicia Constitucional Ecuatoriana, Corporación Editora Nacional, Quito 2004).

Tan solo recientemente ha aparecido un volumen colectivo titulado Derecho Procesal Constitucional (Corporación Editora Nacional, Quito 2005) coordinado 
por el constitucionalista y magistrado español Pablo Pérez Tremps, quien en la introducción dice que los trabajos ahí reunidos escritos por varios autores se dedican al análisis de los procesos constitucionales que son distintos a los demás y de ahí la particularidad del denominado "derecho procesal constitucional". Afirmación preliminar y genérica, sobre la cual el resto de trabajos no vuelve ni ahonda.

En el Perú el término "derecho procesal constitucional" fue introducido por vez primera en 1971 (cf. Domingo García Belaunde, El Habeas Corpus interpretado, I nstituto de InvestigacionesJurídicas de la Universi dad Católica, Lima 1971, p.21) y ha tenido desde entonces un continuo desarrollo hasta la actualidad, acompañado por la promulgación y puesta en vigencia del Código Procesal Constitucional desde el 1 de diciembre de 2004. Y por la intensa actividad jurisprudencial del Tribunal Constitucional.

Quien ha dedicado largos años a estudiar los contenidos, sin titularlo con el nombre, es Víctor Julio Ortecho Villena, desdela ciudad norteña deTrujillo, en sucesivas publicaciones que rematan, por así decirlo, con su sugestivo libro Procesos constitucionales y su jurisdicción, Editorial Rodhas, 9na edición, Trujillo 2004.

Pero el primer texto independientequeutiliza la nomenclaturaesel deGerardo Eto Cruz, Introducción al Derecho Procesal Constitucional, Trujillo 1990-1992, si bien es demasiado escueto.

Más persistentees el esfuerzo desplegado por Elvito A. Rodríguez Domínguez quien hace un planteo de sumo interés desde una óptica procesal en su ponencia Derecho Procesal Constitucional peruano (en "Notarius", año II, núm. 2, 1991) que reelabora y amplía en su obra Derecho Procesal Constitucional, Edit. Grijley, Lima 1997, que es en puridad el primer libro sobre la materia que se publica en el Perú. Y que es fruto de los afanes de un procesal ista, que además enseña la disciplina en la vieja Universidad de San M arcos. El éxito de la obra lo llevó a una siguiente edición en 2002 y final mente a una tercera totalmente revisada y con nuevo nombre, Manual de Derecho Procesal Constitucional, Edit. Grijley, Lima 2006, con extenso prólogo deHéctor Fix-Zamudio.

El siguientelibro sepublica igual menteen Trujillo, cuyo autor Domingo García Belaunde da el título a la obra, Derecho Procesal Constitucional, Edit. Marsol, 
Trujillo 1998 a cargo y con extenso estudio preliminar de Gerardo Eto Cruz. Una segunda edición, revisada y prácticamente doblada en su extensión, ha sido publicada en la Editorial Temis (Bogotá 2001). De larga influencia es su opúsculo Dela jurisdicción constitucional al Derecho Procesal Constitucional, Edit. Grijley, 4ta edición, Lima 2002, quecuenta con una edición en M éxico.

César Landa publica su Teoría del Derecho Procesal Constitucional, Editorial Palestra, Lima 2004 continuando sus importantes estudios sobre el tema, en especial desu voluminoso y bien documentado libro Tribunal Constitucional y democracia, Edit. Palestra, 2da edición, Lima 2004. Sus reflexiones últimas se encuentran reunidas en un denso volumen: Estudios sobre Derecho Procesal Constitucional, Biblioteca Porrúa de Derecho Procesal Constitucional, M éxico 2006. Sin embargo Landa no hace un mayor desarrollo del tema, pues se afilia a la tesis de Häberle al considerar que el "derecho procesal constitucional" es en realidad parte del Derecho Constitucional, al cual "concretiza" con motivo de la actividad jurisprudencial del Tribunal Constitucional. Su enfoque, interesante sin dudas, es algo aislado dentro de la tratadística peruana.

Samuel A bad Yupanqui ha realizado diversos estudios sobre el A mparo. Y desdeuna moderna postura procesal, ha publicado un enjundioso texto titulado Derecho Procesal Constitucional, Ed. Gaceta Jurídica, Lima 2004, que al ser parte de su tesis doctoral, asume una descripción de la disciplina en forma orgánica y ordenada, abordando sus principales problemas. Es quizá la mejor obra informativa y de anál isis dentro de la literatura peruana.

Finalmente, A níbal Quiroga León, procesalista de trayectoria, ha reunido diversos ensayos en su reciente libro Derecho Procesal Constitucional y el Código Procesal Constitucional , A ra Edit. Lima 2005. N o obstanteque Quiroga se ha dedicado desde hace muchos años al tema, promoviendo diversas publicaciones sobre la "jurisdicción constitucional" (en 1990 y bajo el auspicio del Fondo Editorial de la Universidad Católica) así como eventos y revistas e incluso ha propiciado desde 1996 un Código Procesal Constitucional, tiene un enfoque con ciertas peculiaridades y no muy preciso. No empece esto, en lo sustancial mantiene un enfoque procesal.

La publicación y puesta en vigencia del Código Procesal Constitucional en el Perú, el primero en su género a nivel iberoamericano (pues el deTucumán es de carácter local y no nacional) ha hecho aumentar en forma vertiginosa las publicaciones sobre el tema, muchas veces usando el título "derecho procesal 
constitucional" por mera convención, pero otros son largos análisis del Código, algunos con muy al to nivel (como es el caso de Carlos Mesía y Luis Castillo Córdova) o con un propósito sobre todo profesional y de apoyo práctico pero no por ello menos importante(Walter Díaz Zegarra, Gustavo Gutiérrez). A lo que hay que agregar las publicaciones y debates surgidos a partir de la jurisprudencia del Tribunal Constitucional, repuesto democráticamenteen 2001 eintegrado con sietemiembros el egidos por el Congreso dela República.

Entre las publicaciones colectivas merecen citarse AA.VV. Derecho Procesal Constitucional, Susana Y. Castañeda Otsu, coordinadora, Jurista editores, 2da edición, 2 vols, Lima 2004 (hay edición boliviana impresa en Cochabamba); AA.VV. El Derecho Procesal Constitucional Peruano, Estudios en homenajea Domingo García Belaunde, 2 tomos, Editorial Grijley, José F. Palomino Manchego, coordinador, Lima 2005 y Susana Castañeda O., Edgar Carpio Marcos, Eloy Espinosa-Saldaña B. y Luis Sáenz Dávalos Introducción a los procesos constitucionales, Jurista editores, Lima 2005. Deutilidad es el Syllabus deDerecho Procesal Constitucional, por JoséF. Palomino M ., Gerardo Eto Cruz, Luis Sáenz Dával os y Edgar Carpio Marcos, Cuaderno dela A sociación Peruana de Derecho Constitucional, Lima 2003. Un análisis puntual y novedoso hecho por un procesalista lo tenemos en Omar Cairo Rol dán, Justicia Constitucional y Proceso deA mparo, Pal estra editores, Lima 2004.

Mención aparte merece la intensa labor desempeñada por la Asociación Peruana de Derecho Constitucional, que dentro de los eventos que organiza siempre dedica un espacio a los temas de Derecho Procesal Constitucional, como se aprecia en el último de ellos, el VIII Congreso $\mathrm{N}$ acional de Derecho Constitucional celebrado en Arequipa(22-24 de setiembre de 2005). Y más recientemente con el auspicio y apoyo brindado a los congresos nacionales deDerecho Procesal Constitucional, el primero de los cuales sellevó a cabo en la ciudad de Huancayo(18-20 de noviembre de 2004) en la Universidad Privada "Los Andes", que corrió a cargo de Miguel Vilcapoma Ignacio. Este I Congreso fue dedicado íntegramentea analizar el recién promulgado Código Procesal Constitucional, queentraría en vigencia meses más tardeen diciembre de 2004.

En Chile hay un interesante movimiento en esta línea desde mediados de los años ochenta del siglo pasado, que es producto del gran esfuerzo de Humberto Nogueira A Icalá, que desde Santiago o desde Talca, ha orientado estos afanes y además ha promocionado encuentros de estudiosos tanto chilenos como de 
otros juristas del área, quehan sido decisivos para el desarrollo dela disciplina en ese país.

Entre los primeros pasos dados por N ogueira seencuentra el haber convocado un Primer Seminario Latinoamericano en la Universidad Central de Santiago de Chile, en octubre de 1987 y bajo el rubro de "justicia constitucional" (cf. La Revista de Derecho, núm. I, enero-junio de 1988y núm. I, enero-junio de 1989). Posteriormente convoca el segundo seminario en la misma ciudad y con el mismo auspicio, pero al cual denomina esta vez como "2da Jornadas de Derecho Procesal Constitucional" y que se lleva a cabo en abril de 1991. Contó con una sel ecta concurrencia de juristas internacionales. Sus actas sepublicaron en dos números sucesivos de La Revista de Derecho (núm. 2, julio-diciembrede1990y núm. 1, enero-junio de 1991).

En fecha reciente, al celebrarse en Santiago el "IV Encuentro Iberoamericano de Derecho Procesal Constitucional" (noviembre de 2006) publicó con antelación las ponencias presentadas al evento que tenía como título genérico "Desafíos del Derecho Procesal Constitucional en la alborada del siglo XXI" en un grueso volumen de más de 800 páginas: Estudios constitucionales, año 4, número 2, Santiago 2006, que reúnetextos queabordan diversos temas deinterés, pero en donde el membrete "derecho procesal constitucional" no es objeto de un desarrollo especial.

Por su parte, Nogueira ha escrito multitud de artículos sobre el tema, serios y documentados, usando diversos rótulos sin mayores precisiones, sea el de justicia constitucional, sea el dejurisdicción constitucional, vinculándolo sobre todo a Chile, y manejando hábilmente datos del Derecho comparado, así como libros centrados en los derechos fundamentales.

Pero recientementeha presentado un texto orgánico de largo alcance, producto de una investigación de aliento: La jurisdicción constitucional y los tribunales constitucional es en Sudamérica en la al borada del siglo XXI, Bi blioteca Porrúa de Derecho Procesal Constitucional, México 2004, a la que ha seguido una edición venezolana con distinto título(Justicia y Tribunales Constitucionales en A mérica del Sur, Editorial Jurídica Venezolana, Caracas 2006) y con posterioridad y con el mismo titulo la actualizada edición peruana a cargo de Palestra editores(Lima 2006)queaquí utilizo.

En esta obra intenta N ogueira Alcalá distinguir entre jurisdicción y justicia constitucional. Así, señala que al hablar de "justicia constitucional" estamos 
haciendo referencia a un contenido val orativo, pero distingue la versión amplia de la versión restringida. En sentido amplio "justicia constitucional" es todo tipo de control quedesempeña el juez, el órgano legislativo o un órgano especial. Así, tenemos que existe una justicia constitucional "política" y una justicia constitucional "jurisdiccional". Esta última es ejercida por órganos de carácter jurisdiccional, de cualquier orden.

Por su parte, la jurisdicción constitucional es una especie de la justicia constitucional, con la finalidad específica de actuar el Derecho de la Constitución y tiene como meta la defensa de la Constitución, con características específicas.

Las breves líneas anotadas no permiten extraer mayores el ementos de juicio, ya queel autor en realidad no tieneen mentela parteteórica y defundamentos, no empecé lo cual nos presenta una obra de investigación prácticamente exhaustiva, casi sin precedentes y de innegable utilidad y mérito.

El patriarca del os constitucionalistas chilenos, A lejandro Silva Bascuñán utiliza el concepto de "justicia constitucional" y señala que el de "derecho procesal constitucional" no es acertado (cf. Tratado de Derecho Constitucional, Editorial Jurídica de Chile, Santiago 2003, tomo IX, pp. 21; es la segunda edición de un anterior tratado publicado originalmente en la década de los sesenta y en tres tomos; Ia actual segunda edición, en colaboración con M aría Pía Silva Gallinato, está en curso y llega a los once tomos...).

Magistrados del Tribunal Constitucional como Juan Colombo Campbell sehan dedicado al tema (cf. Funciones del Derecho Procesal Constitucional en "Anuario de Derecho Constitucional Latinoamericano", 2002) quien defiende su categoría procesal, pero sin mayores precisiones. En el mismo sentido Luz Bulnes, y con anterioridad I smael Bustos Conchay Lautaro Ríos Álvarez, pero con matices diferenciales. En la línea de investigaciones puntuales, hay que mencionar la meritoria obra de Gastón Gómez Bernales.

A Francisco Zúñiga Urbina sedebeel más completo tratamiento dela disciplina que ha aparecido en ese país, pues toma como referencia no solo la parte doctrinaria, sino la histórica, comparada, legislativa y la propiamente chilena (cf. Elementos de jurisdicción constitucional, Universidad Central de Chile, 2 tomos, Santiago 2002). Acepta el planteo que distingue el "derecho procesal constitucional" del "derecho constitucional procesal", pero no la distinción 
entre justicia y jurisdicción constitucional. Ofrece, por lo demás, un desarrollo muy completo y sugestivo desuma utilidad.

Andrés Bordalí Salamanca es un procesalista que ha incursionado desde su especialidad en el tema, al cual asigna carácter procesal, como se veen su libro Temas de Derecho Procesal Constitucional, Edit. Fallos del Mes, Santiago de Chile2003. Posteriormente, sin embargo, ha coordinado un colectivo con nombre distinto: Justicia Constitucional y Derechos Fundamentales Lexis-Nexis, Santiago 2006.

Con anterioridad, un procesalista acreditado intentó ubicarse, si bien muy ampliamente, en la problemática: Raúl Tavolari Oliveros, H abeas Corpus, Edit. Jurídica de Chile, Santiago 1995.

Bolivia se ha incorporado al debate sobre la temática, a raíz de la fundación y puesta en funcionamiento desu Tribunal Constitucional, queha hecho posible gran cantidad de publicaciones en torno a los procesos y a la actividad del Tribunal (entre otros, AA.VV La justicia constitucional en Bolivia 1998-2003, Tribunal Constitucional, Sucre 2003). Así, Pablo Dermizaky Peredo, maestro dedicado al Derecho Público (tiene sendos manuales sobre Derecho Constitucional y Derecho Administrativo) ha incursionado en el tema, pero con el título de "justicia constitucional" que se emplea incluso en los seminarios que organiza periódicamente el Tribunal Constitucional, del cual Dermizaky fue presidente (1999-2001).

Así, en su importantelibro Justicia Constitucional y Estado deDerecho, Editorial Alexander, 2da edición, Cochabamba 2005, señala en el prólogo que "justicia constitucional" es un sistema elaborado por la doctrina, la legislación y la jurisprudencia aplicables al control, defensa e interpretación de la Constitución... agregando que la justicia constitucional se materializa a través de la jurisdicción constitucional, que es el conjunto de órganos y normas diseñados para administrar aquélla..... de esta manera, la jurisdicción constitucional es el medio y la justicia constitucional es el fin (concepto que repite en la pág. 177 ss.). Este libro de Dermizaky debe ser completado, en cuanto a procesos se refiere, con el siguiente: Derechos y garantías fundamentales, Editorial Alexander, 1ra edición, Cochabamba 2006.

Un primer síntoma denuevas inquietudes es el libro colectivo Derecho procesal constitucional boliviano, con colaboraciones de Francisco Fernández Segado, 
Jorge A sbún, Pablo Dermizaky, Willman Durán Rivera, William Herrera, José Antonio Rivera y Víctor Bazán (editado por la A cademia Boliviana deEstudios Constitucionales, Santa Cruz 2002) en donde el tema es asumido pero no desarrollado.

Desdeuna óptica procesal seencuentra el libro deJ osé Decker Morales, Derecho Procesal Constitucional, s/ e, Cochabamba 2002, en donde condensa inquietudes formuladas desde 1998, cuando por primera vez usó el concepto en el país.

El más completo estudio sobreel tema sedebeaJ oséA ntonio Rivera Santibáñez, quién fuera magistrado constitucional, y que ha publicado un enjundioso volumen sobre la Jurisdicción constitucional (Grupo Editorial Kipus, 2da edición, Cochabamba 2004; la primera edición es de 2000) en donde dedica una primera parte, muy amplia, a la discusión académica sobre el concepto, y se afilia a una tendencia procesal. Rivera además es un constante animador de estos temas, con gran capacidad de convocatoria, como lo demuestran los eventos organizados en La Paz y Santa Cruz.

Un planteo doctrinario bastante ceñido y con un amplio desarrollo de la problemática boliviana, con un enfoque procesal y con referencias jurisprudenciales, lo tenemos en René Baldivieso Guzmán, Derecho Procesal Constitucional, Ind. Gráficas Sirena, Santa Cruz de la Sierra 2006, sumamente útil, pues su autor fue magistrado del Tribunal Constitucional.

En Uruguay existe una larga tradición manualística en materia constitucional, queincluye dentro desu ámbito el problema del control de constitucionalidad, al cual general mente no se califica en forma independiente(al gunos le llaman justicia constitucional) ni tampoco se enfoca como algo que merezca ese tratamiento(así en los textos de Jiménez de A réchaga, José Korseniak, Rubén Correa Freitas, M artín Risso Ferrand, etc.) Pero el primero que usa el concepto en ese país es el eminente procesalista Eduardo J. Coutureen su obra Estudios de derecho procesal civil, 3 tomos, Ediar, Buenos Aires 1948-1950 (con reimpresiones) que probablemente tomó de los trabajos de Alcalá-Zamora y Castillo,a quien conocía y trataba por frecuentar la comunidad jurídica argentina, en dondeA Icalá-Zamora vivía en aquellaépoca.Sin embargo, Couture no hace ningún análisis conceptual, sino que se limita (en el tomo I) a dar el título de "Casos de derecho procesal constitucional" a una sección que agrupa diversos ensayos alusivos y sobre el cual no se arroja luz alguna. 
Años más tarde se encuentra un desarrollo más elaborado que debemos a Eduardo G.Esteva Gallicchio, que lo pone en discusión en 1984 y en donde hace un distingo entre el "derecho procesal constitucional" por un lado, y el "derecho constitucional procesal" por otro (cf. Lecciones de introducción al Derecho Constitucional. Derecho Constitucional, I, tomo I, M ontevideo 1984, tomol, pp. 9-10).

De parte de los procesalistas merece un tratamiento especial la obra, no muy extensa pero bien elaborada, de Enrique Véscovi, quien le da un tratamiento netamente procesal, si bien no arriesga un planteo doctrinario ni tampoco un nombre moderno(cf. El proceso de inconstitucionalidad de la ley, Facultad de Derecho y Ciencias Sociales, Montevideo 1967; Principios estructurales del proceso constitucional en "Universidad", Universidad Nacional del Litoral, Santa Fe, set-dic de 1969, núm. 79. Y Los recursos judiciales y demás medios impugnativos en I beroamérica, Edit. Depalma, Buenos Aires 1988; a pp. 463ss. se inclina por el uso del término "jurisdicción constitucional").

En lo que se refiere al Paraguay no he encontrado una sola referencia sobre el tema quenos ocupa, si bien hay estudios en torno a él (cf. Juan Carlos M endonça, Inconstitucionalidad. A spectos procesales, Editorial El Foro, A sunción 1982; Luis Lezcano Claude, El control deconstitucionalidad en el Paraguay, Edit. La Ley Paraguaya, A sunción 2000; ib. La defensa de la Constitución en el Derecho Paraguayo, en AA.VV. "Defensa de la Constitución-Garantismo y controles", Libro dereconocimiento a Germán J. Bidart Campos, Víctor Bazán, coordinador, Ediar, Buenos Aires 2003.

\section{CENTROAMÉRICA Y EL CARIBE}

En Centroamérica, el país que más producción tiene en la materia que nos ocupa es sin lugar a dudas Panamá, queal igual que otros países desu entorno, ha tenido facilidades para que sus estudiosos sal gan al exterior a formarse y ponerse al día en novedades bibliográficas. Así tenemos que en Panamá se publica el libro de Sebastián Rodríguez Robles titulado Derecho procesal constitucional panameño (Universidad de Panamá, Panamá 1993) basado en la tesis de grado que presenta su autor ante el correspondiente centro universitario y quees la primera publicación en forma delibro aparecida en ese país y probablemente en toda Centroamérica. El autor tuvo la suerte de estar cerca del maestro César Quintero (1916-2003), de reconocido prestigio internacional y queprologó el libro haciendo un amplio como meditado estudio 
sobre las variantes del proceso y sus relaciones con la Constitución. Y además siguió estudios depostgrado en laA rgentina, lo cual lepermitió estar en contacto con la más calificada doctrina sobre la materia. Y si bien la obra está centrada en el desarrollo y análisis dela dogmática panameña vigentea la época en que formuló su trabajo, lo antecede con un brevepero centrado análisis conceptual sobre la disciplina.

Rodríguez Robles parte del concepto de Derecho Procesal y sin mayores vacilaciones señala queel Derecho Procesal Constitucional es una desus ramas o disciplinas, si bien reconoce la dificultad de fijar sus contornos doctrinarios. Tampoco hace concesiones a figuras próximas o vecinas. Y tentativamente define el Derecho Procesal Constitucional como el conjunto defundamentos doctrinales y preceptos normativos de carácter instrumental, instituidos para asegurar eficazmenteel estricto cumplimiento de la ley suprema del Estado (es decir, de la Constitución; pág. 59).Y ella incluye las garantías constitucionales jurisdiccionales, las garantías constitucionalizadas del control de legalidad, así como las garantías implícitas del debido proceso.

La segunda publicación quetenemos es la de Boris Barrios Gonzáles (Derecho Procesal Constitucional, Edit. Portobelo, 2da edición, Panamá 2002; la primera edición es de 1999). Según su autor, cuyo manual ha tenido una amplia circulación, el Derecho Procesal Constitucional tiene carácter instrumental de natural eza pública y reglamenta el ejercicio de la jurisdicción constitucional. En tal sentido, su obra se dedica a desarrollar procesos tales como el A mparo, el Habeas Corpus, Ia A cción de Inconstitucionalidad, etc. tal como se dan en la experiencia panameña.

Rigoberto González M ontenegro ha publicado un Curso de Derecho Procesal Constitucional (Litho Editorial Chen, 2daedición, Panamá 2003; primera edición en 2002) en donde acepta que el Derecho Procesal Constitucional es rama específicamente procesal para la defensa de la Constitución. Es por tanto una disciplina autónoma y sus contenidos son: a) jurisdicción b) procesos y c) órganos.

Y por cierto, hay otros enfoques que utilizan un esquema más convencional y que dan cuenta de la temática en el respectivo país (cf. Heriberto Araúz, Panorama dela justicia constitucional panameña, Universal Books, 1ra. edición, Panamá 2003). Si bien en algunos casos, se utilizan los conceptos en forma heterodoxa; cf. JorgeFábrega P. Derecho Constitucional Procesal Panameño, en 
AA.VV. "Estudios de Derecho Constitucional Panameño", Editora Jurídica Panameña, Panamá 1987. U otros que dentro detítulos convencionales, utilizan en su interior el concepto de "derecho procesal constitucional" (como es el caso deEdgardo Molino Mola, La jurisdicción constitucional en Panamá, 2da edición, Copicentro edit., Panamá 2002).

En Nicaragua se cuenta con la ingente producción de Iván Escobar Fornos, quien ha incursionado en varios temas jurídicos, en especial relacionados con el Derecho Civil, pero a nuestro tema ha dedicado un volumen titulado Derecho Procesal Constitucional, H ispamar, M anagua 1999. En ella acepta al Derecho Procesal Constitucional como instrumental, lo cual es expresión o desarrollo de un tema más amplio como es la justicia constitucional, pero sin entrar en mayores detalles. Posteriormente, esta obra es objeto deun replanteo y reelaboración y la publica como Introducción al Derecho Procesal Constitucional (Biblioteca Porrúa de Derecho Procesal Constitucional, M éxico 2005). Aquí amplía y precisa algunos conceptos; acepta un Derecho Constitucional Procesal al Iado del Derecho Procesal Constitucional, desarrolla notablemente la parte conceptual y comparada y señala que el contenido del Derecho Procesal Constitucional lo integran; i) la justicia constitucional, ii) los órganos de control, iii) las garantías constitucionales, iv) las partes y v) el proceso.

País de gran tradición cultural es Costa Rica dentro del ámbito centroamericano.La figura más importante, no solo por su obra sino por su magisterio es Rubén Hernández Valle, quien tempranamentepublica su Derecho Procesal Constitucional (Edit. Juricentro, San José 1995; 2da edición, 2001). Hernández asume que estamos ante una rama del Derecho Procesal que se dedica a estudiar los instrumentos delajurisdicción constitucional y los procesos constitucionales (pp. 31-36 dela 2da edición). Sin embargo, entre una edición y otra publica Escritos sobre justicia constitucional (Biblioteca Jurídica Diké, Medellín 1997) en dondeel cambio del título provieneprobablemente, tal como señala el autor, por tratarse de unas lecciones preparadas para impartirse en Madrid y que no alcanzó a llevar a cabo. Pero en ellas desarrolla las bases del "Derecho Procesal Constitucional".

Este último libro y otros ensayos del autor fueron publicados luego bajo otro título en la Bi blioteca Porrúa de Derecho Procesal Constitucional, queen M éxico dirige Eduardo Ferrer Mac-Gregor. Y más recientemente en un volumen compilativo bajo el título de Derechos fundamentales y jurisdicción 
constitucional, Jurista editores, colección dirigida por Susana Castañeda y publicado en Lima en 2006. Y del que seprepara una edición boliviana.

Rodolfo Piza E. quien duranteaños fuera connotado magistrado dela prestigiosa Sala Constitucional de Costa Rica, intentó una peculiar distinción entre "justicia constitucional" y "jurisdicción constitucional" que no ha tenido seguimiento (vid. su artículo Justicia constitucional y Derecho dela Constitución en AA.VV., "La jurisdicción constitucional", III Aniversario de la creación de la Sala Constitucional, Edit. Juricentro, San José 1993).

Pero la doctrina también usa, como equivalentes, los conceptos de "jurisdicción constitucional" y "justicia constitucional" (cf. Alex Solís Fallas, La dimensión política de la justicia constitucional, Imp. Gráfica del Este, San José 2000).

Guatemala es un país de grandes tradiciones, sobre todo en materia constitucional y de defensa dela Constitución, y en dondeademás se instaura una Corte de Constitucionalidad en 1965 , si bien peculiar y con funcionamiento intermitente y que posteriormente ha tenido un desarrollo interesante. Tiene una vida cultural activa, pero ha desarrollado el tema que nos ocupa dentro del campo constitucional o en el denominado "defensa de la Constitución" en donde hay varios trabajos val iosos de Jorge Mario García Laguardia (cf. entre otros, La defensa de la Constitución, Guatemala 1983). La literatura, por lo demás, engl oba el problema procesal constitucional dentro delos libros o textos sobrela Constitución, quees calificado como justicia constitucional (cf. Gerardo Prado, Derecho Constitucional, Editorial Praxis, 4ta edición, Guatemala 2005y Juan Francisco Flores Juárez, Constitución y Justicia Constitucional, Publicación de la Corte de Constitucionalidad, Guatemala 2005).

En el Caribehay quemencionar, por su gran tradición cultural, el caso de Cuba. En la etapa pre-revolucionaria heencontrad o un referente importanteen la obra deFernando Álvarez Tabio, con valiosas obras en materia civil, constitucional y procesal. Así, en su libro El recurso de inconstitucionalidad (Editorial Librería Martí, La H abana 1960) estudia esteproceso, delarga data en Cuba pero tal como estaba regulado en la Ley del Tribunal de Garantías Constitucionales y Sociales de 1949, quedesarrolla la institución creada por la Constitución de 1940. Diceen su introducción que dicha ley contiene el conjunto de normas ordenadoras del recurso de inconstitucionalidad, es decir, constituye "la fuente principal del Derecho Procesal Constitucional". Y agrega que "no es posible, pues, emprender el estudio de una rama del Derecho Procesal sin ponerlo en contacto con la teoría 
general del proceso". A continuación señala que "el concepto del proceso es el núcleo primario de todo el complejo de problemas queimplica el estudio de un ordenamiento procesal". Cita como sus fuentes a diversas autoridades del mundo procesal (Redenti, A lcalá-Zamora, Goldschmidt, Guasp, etc.) y haceun desarrollo delainstitución en esalínea. Álvarez Tabio con posterioridad seadhirió al régimen castrista y perpetró un extenso comentario a la Constitución cubana de 1976, que no tiene la altura quegozan sus otros textos jurídicos y por cierto no volvió sobre losmismostemas (cf.Comentarios ala Constitución socialista, Ediciones) urídicas, La Habana 1981).

Con posterioridad esteenfoquesefueperdiendo dentro del torbellino político existente y se retomó el tema años más tarde, dentro de una ideología política determinada. Desapareció el control jurisdiccional que existía y seintrodujo el control político, que en realidad no es control o en todo caso no es eficiente. Y además, desdeun enfoquemuy general y sin precisiones. Y con el uso, cada vez más frecuente del vocablo "justicia constitucional" (cf. Julio Fernández Bulté, Los desafíos dela justicia constitucional en A mérica Latina en los umbrales del siglo XXI en "Revista Cubana de Derecho", núm. 11, 1996). Este destacado jurista cubano nos dice en este ensayo que "no tendríamos una visión medular sobre la justicia constitucional en nuestro subcontinente, si no entendemos y medimos en todo su calado los rumbos que emprende el capital ismo mundial en su actual reacomodo o reajuste". Con lo que pone de relieve que el sistema adoptado en Cuba obedece a la defensa deuna filosofía política determinaday no a un control del poder.

En forma más clara lo expone detalladamenteM artha Prieto Val désen un ensayo medular:

“....para el análisis de este sistema de defensa debe partirse de un grupo de características básicas de los sistemas, político y jurídico, como son el monopartidismo, ausencia deoposición legalizada y la organización del Estado sobre determinados principios que aseguran la unidad de la acción politica a todos los niveles del territorio... en la esfera económica, la dirección, ejecución y control es estatal, una hacienda centralizada....en síntesis; las hondas transformaciones socioeconómicas y políticas impusieron una nueva legalidad, una nueva forma de hacer, con la necesidad de cumplir las decisiones, no de discutirlas, de centralizar el poder, no de separarlo y equilibrarlo; se aprobó una Constitución que es punto esencial departida para el desarrollo, reflejo de las conquistas alcanzadas y no un límite del poder...." 
“..Tal diseño provoca, en materia de control constitucional, la existencia del modelo de control político-abstracto, concentrado y posterior." (cf. El sistema de defensa constitucional cubano, en "Revista Cubana de Derecho", núm. 26, julio-diciembre de2005).

Y estos principios quehacen depender el control del poder deuna determinada concepción de la "revolución" que inspira el régimen,que se define como "democracia socialista" es lo que se enseña pacíficamente en los centros universitarios de ese país(cf. Lissette Pérez Hernández y Martha Prieto Valdés,Temas deDerecho Constitucional Cubano, Edit. Félix Varela, La Habana 2000). Y en donde el concepto de "derecho procesal constitucional" no atrae la atención y eventual mente se ignora, como se aprecia en diversos estudios(cf. entre otros Juan Mendoza Díaz, Hacia una concepción unitaria del Derecho Procesal en Cuba en "Revista Cubana de Derecho", núm. 26, julio-diciembre de 2005).

En lo quese refiereala República Dominicana, hay quedestacar quesu peculiar historia politica leha impedido no solo una mayor estabilidad para desarrollar sus instituciones, sino un mayor desarrollo en temas culturales, pues estos vaivenes al canzan hasta period os relativamentecercanos a nuestros días(como es el caso de la denominada "era de Trujillo" que va desde 1930 a 1961). Y que seprolonga al gunos años más como sucedesiempre cuando caeuna dictadura y no existenada que lo remplace o fuerzas que ayuden a construir al go nuevo, lo que solo se ve en los últimos tiempos. Y esto sin desconocer la existencia de ciertas figuras que han influenciado en el mundo cultural, como es el caso de Eugenio María de Hostos, cuyas Lecciones de Derecho Constitucional se publican en Santo Domingo en 1887 y luego en versión definitiva y póstuma en París en 1908(a partir de la cual se han hecho varias reimpresiones). Y que ha tenido larga influencia en el Caribey en nuestra A mérica.

En lo referenteal tema delajurisdicción constitucional, seha seguido en general la tendencia existente en América Latina (cf. Juan Jorge García, Derecho Constitucional Dominicano, UCMM, Santiago, Rep. Dominicana, 1984) tratándose dentro del área constitucional y contándose también con algunos estudios monográficos sobre el particular (en materia de control de constitucionalidad, A mparo, etc.). Así, Rafael Luciano Pichardo y José Hernández Machado presentan un panorama de la situación en una reunión de magistrados en el Brasil en una ponencia que tiene el significativo titulo siguiente: La evolución del Derecho Procesal Constitucional a través de los 
órganos judiciales de la República Dominicana y que se ha publicado posteriormente en diversas revistas(aquí lo tomamos del "Anuario de Derecho Constitucional Latinoamericano", Montevideo 2002) si bien no hay ninguna definición ni explicación al empleo de tal nombre, queal parecer es la primer vez que se usa en la doctrina jurídica dominicana. N o obstanteesto, el primero de los nombrados publicaría tiempo después el importante folleto La justicia constitucional, Santo Domingo 2006, en donde desarrolla el control de la constitucionalidad y el Amparo, pero sin entrar al tema doctrinario o de fundamentos.

Al margen de esto, tenemos al gunos textos de carácter general sobre Derecho Constitucional, entrelos que destaca el denso y bien documentado deEduardo Jorge Prats, Derecho Constitucional, 2 da edición, Ed. GacetaJudicial, 2 tomos, Santo Domingo 2005 y en donde se hacen diversas referencias al "derecho procesal constitucional" y a la literatura que lo desarrolla o comenta, pero sin mayores precisiones (entre otros vid. el tomo I, pág. 339; la primera edición dela obra es de 2003).

En el Caribequeda además un país importante: Puerto Rico, actualmente como Estado Libre A sociado de los Estados Unidos. Lo que ha hecho queen materia de Derecho Público esté muy influenciado por el llamado "modelo americano" que no conoceeste tipo deinquietudes y queviveal margen deellos.

\section{LOSINCIOSEN LA ARGENTINA. EL PLANTEO DE SAGÜES}

No obstanteel enfoquefundacional deAlcalá-Zamora y Castillo al queya me he referido, éste no tuvo ningún eco en la A rgentina de aquel entonces, sino que pasó desapercibido al igual que en M éxico durante los primeros años de su forzado exilio. El tema vuelve a plantearseen la Argentina y por obra deun jurista argentino, tan solo en 1979 y en la obra monumental de N éstor P. Sagüés.

En efecto, en 1979Sagüés publica su libro Ley deA mparo (Edit. A strea, Buenos Aires), que en realidad encierra un amplio como profundo análisis de la institución desde el punto de vista doctrinario, histórico, legislativo-a nivel nacional y provincial-y jurisprudencial. Es en ese momento que con claridad, pero sin mayor detenimiento, hace referencia al A mparo como institución del Derecho Procesal Constitucional (pág. 64) apoyándose para ello en la reseña bibliográfica deA Icalá-Zamora de 1945, ya referida. 
Posteriormente, Sagüés publica un ensayo maduro y sólido, al cual se ha mantenido fiel a través de los años, titulado "Derecho Procesal Constitucional y jurisdicción constitucional" (La Ley, 1981, C, pp.865-871). Ahí sostiene básicamente lo siguiente:

a. Que es necesario partir del concepto de "jurisdicción constitucional", no empecesu imprecisión, toda vez queéste ha sido el referente para estudiar la disciplina que tiene el nombre de "derecho procesal constitucional", de la cual incluso existeun libro reciente(se refiereal deJesús González Pérez publicado en Madrid en 1980).

b. En cuanto a la jurisdicción constitucional, entiende que hay dos enfoques: el material y el orgánico. Lo material otorga esa potestad a cual quier órgano, cualquiera que fuese, que pueda decir el derecho en materia constitucional. Lo orgánico lo limita a la existencia de un órgano especializado y cal ificado, como lo es un tribunal o corteconstitucional. Sagüés entiendequeel concepto material es preferible, ya que si no es así, muchas cosas se quedan sin explicar, como por ejemplo, la experiencia jurisprudencial argentina.

c. Merece también la atención de nuestro autor el tema de la magistratura constitucional y el proceso constitucional. En ambos casos opta por un enfoque material.

d. En cuanto al contenido del Derecho Procesal Constitucional, señala que lo constituyen los procesos constitucionales y la magistratura constitucional.

e En cuanto al origen dela disciplina atribuido a Kelsen, anota quesin negar los méritos y aciertos del maestro de Viena, ello no puede considerarse exacto, toda vez que existen instrumentos de defensa que se remontan a cientos de años atrás, que precisamentehoy son parte de la disci plina, por lo que tal paternidad resulta exagerada.

f. En cuanto a la ubicación del Derecho Procesal Constitucional, es partidario deseñalarla como una discipl ina mixta, quegoza delas bondades y materias tanto del Derecho Procesal como del Derecho Constitucional, constituyendo una suerte de tertium genus que nace a partir de aquéllas.

Este ensayo, realmente fundamental, es el primero que con esa envergadura se publica en la Argentina. Es cierto queello es posible por diversas circunstancias 
que hay quetener presente, como son la presencia deA Icalá-Zamora y Castillo, el movimiento procesal y constitucional argentino (ésteúltimo muy activo desde principios del siglo XX), la jurisprudencia de la Corte Suprema, la realización en Sochagota (Colombia) del II Coloquio I beroamericano dedicado en exclusiva al tema de la Jurisdicción Constitucional, que es el primero en su género en el mundo hispanohablante (en 1977) y las propias inquietudes del autor y desu entorno generacional.

Al volumen sobrela ley deA mparo de 1979, sigueel dedicado al Habeas Corpus (1981) y posteriormente al Recurso Extraordinario (2 vols., 1984). Con posterioridad, a partir de la década del ochenta (1989) los cuatro volúmenes aparecen unificados y reordenados bajo el rótulo genérico de "derecho procesal constitucional", si bien con independencia temática. Y desde entonces ha circulado así con varias ediciones (el ordenamiento ahora es el siguiente: tomos I y II: Recurso Extraordinario, tomo III: Acción deA mparo y tomo IV: Habeas Corpus).

Lo significativo es que el tomo I que inicia la colección y que está dedicado al "Recurso Extraordinario" tiene ahora una larga introducción de carácter doctrinario, en donde el autor recoge, casi textualmente y con algunos aditamentos, su ensayo de 1981, que lesirve así para cubrir todo el panorama. Añadesin embargo algunas notas: siguiendo a Fix-Zamudio admitela existencia deun Derecho Constitucional Procesal (queperteneceal ámbito constitucional) al lado del Derecho Procesal Constitucional (quees rama procesal) y aprovecha para citar la doctrina argentina quea ese momento se ha ocupado del tema (en la cuarta edición de 2002 quees la quemanejo, a pp. 18-24) en donde se aprecia que es en la década del ochenta del siglo pasado que empiezan tímidamentea aparecer publicaciones dedicadas al tema y así continua hasta el presente en ritmo creciente. A lo que hay que añadir las jornadas o congresos sobre la materia, de las que el mismo Sagüés es animador o impulsor, como son las Jornadas A rgentinas deDerecho Procesal Constitucional (la última delas cuales, la IX, sellevó a cabo en la Universidad EI Salvador, en Buenos Aires en setiembre de 2006). A lo que debe agregarse la fundación del Centro Iberoamericano de Derecho Procesal Constitucional (en Rosario y en 1992)queluego setransformó sin solución de continuidad, en el Instituto I beroamericano deDerecho Procesal Constitucional con motivo del I Encuentro I beroamericano de Derecho Procesal Constitucional real izado en Rosario(21-22 de agosto de 2003). Posteriormente sehan realizado el II Encuentro(San José, julio de 2004) III Encuentro(A ntigua, diciembrede 2005) y IV Encuentro(Santiago deChile, noviembre de 2006). 
La obra posterior de Sagüés es amplia y ha tocado diversos tópicos. N o solo se ha dedicado a corregir y actualizar su obra en cuatro tomos que ha gozado de vasta difusión, sino a publicar otros libros de diverso signo, y en especial uno sobre "elementos de derecho constitucional" y otro sobre "teoría de la Constitución" que han tenido gran aceptación y que reflejan sus reflexiones y aportaciones a tal es temas. A lo quehay agregar cantidad deensayos dediverso calibre publicados en revistas jurídicas especial izadas de la Argentina y de otros países (Ios más importantes reunidos en El sistema de derechos, magistratura y procesos constitucional es en A mérica Latina, Biblioteca Porrúa de Derecho Procesal Constitucional, M éxico 2004 y Derecho Procesal Constitucional. Logros y obstáculos, Ed. Ad-hoc, Buenos Aires, 2006). Y sin descontar el importante abordaje a los ordenamientos procesal es provinciales argentinos, como se aprecia en el libro Derecho Procesal Constitucional de la Provincia de Santa Fe, Rubinzal - Culzoni Edit., Bs. Aires 1999, escrito en colaboración con M aría M ercedes Serra.

Lo importante en la obra de Sagüés es que por el carácter temprano de sus escritos, la perseverancia queha puesto en ell os y la solidez desus afirmaciones, hechas con sindéresisy aval ados por una bi bliografía de primera mano, lo han colocado en un puesto de avanzada en la comunidad jurídica argentina, en dondeha contribuido en forma decisiva no solo a queseahonden y cultiven los temas del Derecho Procesal Constitucional, sino que se realicen eventos académicos, se funden asociaciones que juntan a sus cultores, se instal en cátedras y se multipliquen los encuentros sobre sus diversos tópicos. Lo cual ha hecho posible que exista una línea de continuidad entre sus aportaciones y lo que ha venido después en generaciones sucesivas. Y sobre todo, que sus planteos hayan pasado a ser un patrimonio común sobre el cual trabaja la nueva generación de estudiosos. Esta labor de por sí impresionante, ha tenido el mérito de pasar las fronteras de su patria, convirtiendo a su autor en un embajador de la disciplina en el resto de nuestros países y en uno de sus más destacados interlocutores.

\section{OTRAS CONTRIBUCIONES ARGENTINAS}

Dentro dela comunidad constitucional argentina la figura deGermán J. Bidart Campos (1927-2004) es señera, por la original idad de sus contribuciones y por la vastedad delos temas que investigó y que dieron materia para susnumerosas publicaciones. Entre ellas cabe señalar su libro pionero Derecho de A mparo (Ediar, Buenos Aires 1961) publicado cuando todavía no se había dado la ley 
de la materia y solo existía la creación pretoriana de la Corte Suprema, y que después amplió y actualizó en su Régimen legal y jurisprudencial del A mparo (Ediar, Buenos Aires 1968). A lo quehay queagregar su libro La CorteSuprema. El Tribunal de las Garantías Constitucionales (Ediar, Buenos Aires 1984) y muy especialmente La interpretación y el control constitucionales en la jurisdicción constitucional (Ediar, Buenos Aires 1987). Bidart Campos estudió agudamente, como es deverse, los procesos constitucionales en la Argentinay los aspectos teóricos de la jurisdicción constitucional, pero con ciertas vacilaciones y sin una aproximación clara a los temas del Derecho Procesal Constitucional, que veía como una asignatura al lado del "Derecho Constitucional Procesal", pero sin adentrarse en ella y sin darle mayor importancia (cf. Tratado Elemental de Derecho Constitucional Argentino 1ra edición, Ediar, Buenos A ires 2005, tomo II-B, pp. 575-576). En realidad, el tal ento deBidart estuvo más atento a otras cosas y casi no dio importancia al aspecto de los fundamentos de esta nueva disciplina, si bien no hay que olvidar sus originales contribuciones al estudio y desarrollo de al gunas figuras procesales constitucionales.

Y en el campo procesal destaca nítidamentela figura deA ugusto M .M orello, de vasta como influyente obra y que se ha acercado a los temas del "derecho procesal constitucional", empleando el nombre, pero sin entrar en mayores elaboraciones doctrinarias (entre otras, vid. Constitución y proceso, Librería Editora Platense, Buenos Aires-La Plata 1998).Veamos ahora al gunas aportaciones especificas.

i. Juan Carlos Hitters: publica un importante ensayo en 1987: El Derecho Procesal Constitucional (en "El Derecho", tomo 121,1987) que es realmente singular por la fecha y por los conceptos que expone, si bien después seha dedicado a otros aspectos del Derecho Procesal y no ha vuelto a tocar el tema (no obstante, su ensayo ha sido reproducido profusamenteen diversos países latinoamericanos desde la década de los años noventa). En este ensayo, $\mathrm{H}$ itters hace una brevehistoria delos orígenes del Derecho Procesal Constitucional, señalando que su característica es estar imbricado dentro del Derecho Procesal. No obstante esto, subraya las relaciones entre el Derecho Constitucional y el Derecho Procesal. Y en cuanto a su contenido básico indica que es el proceso constitucional que abarca cuatro vertientes: i) el debido proceso legal, ii ) las garantías de las partes, iii) las categorías de la jurisdicción, y iv) las garantías judiciales. Y dentro de este ámbito, la protección de los derechos humanos ocupa un lugar importante. 
La obra posterior deHitters, degran envergadura, seha enrolado en aspectos netamente procesales, así como sobre la protección internacional de los derechos humanos.

ii. Osval do A. Gozaíni tieneuna amplia producción dedicada al tema. Salido de las canteras procesales argentinas en donde tiene abundante y sólida obra, percibió muy pronto la existencia o por lo menos la necesidad de un Derecho Procesal Constitucional (así en su libro Introducción al nuevo Derecho Procesal, Ediar, Buenos A ires 1988) en donde una de sus partes está dedicada a un trazado somero de la disciplina.

Pero es en su libro La justicia constitucional (Edic. Depalma, Buenos Aires 1994) dondehaceun planteo más amplio, señala su trayectoria, contenidos y las acciones o procesos constitucionales involucrados. Aun más, afirma su raíz procesal, si bien el título de la obra es otro, al parecer tomado como sinónimo. Fruto de la misma investigación, aparece en M éxico en 1995 y bajo el sel lo de la Universidad Nacional Autónoma de México (UNAM) el libro EI Derecho Procesal Constitucional y los derechos humanos en donde reitera conceptos anteriores. Val ela pena señalar queestelibro es el primero que en México usa en su título el de "derecho procesal constitucional", no obstante que el nombre figuraba con anterioridad en artículos y ensayos publicados en revistas especializadas de ese país.

Replanteando lo anterior, pero a su vez como suma de todo ello, inicia la publicación desu Derecho Procesal Constitucional, siguiendo la huella de Sagüés, y destinado a ser publicado en cinco tomos, desarrollando la dogmática argentina desde perspectivas doctrinarias.

El tomo I (Editorial de Belgrano, Buenos Aires 1999) confirma y afina lo antes expuesto, de lo que debemos destacar al gunas notas:

a. afirma que el Derecho Procesal Constitucional es una disciplina autónoma,

b. sin llegar bien a ubicarla, se inclina a considerarla como disciplina mixta, o sea, emparentada pero no identificada con el Derecho Procesal y el Derecho Constitucional,

c. tiene por objeto las garantías, los procesos y la magistratura,

d. existe una suerte de escal onamiento de distintas disciplinas que interactúan entresí: 

i) Derecho Procesal Constitucional,
ii)Derecho Constitucional Procesal, $y$,
iii)Derecho Procesal Transnacional.

Con posterioridad al tomo I (en donde hace una breve referencia a los procesos constitucionales) publica el tomo II (Habeas Data, 2001) el tomo III (Amparo, 2002) el tomo IV (El debido proceso, 2004) y el tomo V (protección procesal del usuario y del consumidor, en 2005).Este último, por su contenido, no parece encajar en la colección.

Final mente, como remate de todo lo anterior, ofrece una Introducción al Derecho Procesal Constitucional (Rubinzal-Culzoni Editores, Buenos Aires 2006) en donde reordena, reitera y precisa lo anterior.

En síntesis, en esta reciente publicación afirma las siguientes tesis:

a. el Derecho Procesal Constitucional es una disciplina autónoma, de carácter procesal.

b. Su contenido está determinado por la magistratura constitucional y por los sistemas procesales específicos; esto último conlleva la interpretación constitucional y los procesos, incluyendo el transnacional (y en términos generales, el debido proceso).

E incluye además otras reflexiones sobre el juez constitucional, el proceso constitucional y sus variantes.

Entiendo que esta última obra representa en cierto sentido una ruptura con algunas de las tesis anteriormente sostenidas por su autor, efectuando avances importantes que seguramente ampliará en el futuro. La obra se cierra con dos apéndices importantes: el Código Procesal Constitucional del Perú (2004) y el anterior aprobado en la Provincia de Tucumán (1999).

iii. A dolfo A.Rivas: se trata de un destacado procesalista, que sin embargo ha dado apoyo y cabida a los estudios de Derecho Procesal Constitucional, como lo demuestra el colectivo publicado por él en colaboración con F.M. Machado Pelloni (2003) el cual recogeimportantes aportaciones, así como su recienteTeoría general del Derecho Procesal, Lexis-N exis, BuenosAires 2005, en donde incorpora al Derecho Procesal Constitucional dentro del ámbito 
procesal y como una desus ramas más jóvenes, dand o cuenta desus cultores, con una amplia como generosa referencia a los juristas queen la Argentina y en general en la A mérica Latina, han dedicado estudios a la disciplina. Es autor, además, deun libro medular: El A mparo, Ediciones La Rocca, Buenos A ires 2003 y ha impulsado diversos encuentros dedicados a la disciplina.

iv. Pablo Luis Manili: anoto su nombre para hacer referencia al reciente y valioso colectivo que ha organizado y publicado (cf. Derecho procesal constitucional, Editorial Universidad, Buenos Aires 2005) que reúne colaboraciones de dieciséis juristas argentinos de las nuevas generaciones, para tratar los instrumentos procesales dedefensa dela Constitución y de los derechos humanos, tal como han quedado configurados en la reforma constitucional de 1994. En su lista de colaboradores encontramos a Marcela I. Basterra, M aría Sofía Sagüés, A ndrés Gil Domínguez, Jorge A. A maya, Eduardo P. Jiménez, A delina Loianno, Marcelo A. López Alfonsín, Calogero Pízzolo, Alberto A. Spota (h), Maximiliano Torricelli, Patricio Marcelo E. Sanmartino, José Miguel Onaindia, Alfredo M. Vítolo, Andrea Gualde, María Ximena Fernández Barone y Carla Vanina Iorio.

Manili antecedeel libro con un extenso como meditado estudio preliminar, en donde siguiendo las huellas de N éstor P. Sagüés señala el nombre, los contenidos y la ubicación mixta del Derecho Procesal Constitucional. La obra, por lo demás, es un excelente esfuerzo colectivo que presenta una ajustada panorámica del actual ordenamiento jurídico argentino y del al to nivel demostrado por sus autores.

v. DeEduardo P. Jiménez hay queseñalar la importante ponencia quepresentó al VIII Congreso Nacional deDerecho Constitucional celebrado en A requipa (Perú) los días 22-24 de setiembre de 2005, titulada A cerca de los orígenes fundacionales del Derecho Procesal Constitucional" (publicado en "Ponencias al VIII Congreso", Colegio de Abogados de Arequipa, 2005 y reproducida en "El Derecho" de 17 de noviembre de 2005). Y en donde retoma, replanteándolos, aspectos que había tratado en un pionero ensayo publicado en 1987. Debedestacarsetambién la intensa actividad académica queJiménez realiza con un grupo de discípulos, en la Universidad de Mar del Plata.

vi. A portes en Córdoba: En un país como la Argentina, los avances y las novedades suelen venir del centro y luego repercuten en la periferia. Sin embargo, hay excepciones y en la materia que nos ocupa es importante la 
situación de Córdoba, cuyas contribuciones de distinto orden no son muy conocidas. En lo quenos ocupa, cabeseñalar queen esta capital deprovincia existe cátedra dedicada al curso de "Derecho Procesal Constitucional" con carácter permanente en la Universidad Nacional de Córdoba y gracias a su influjo han sal ido hasta ahora dos manuales quehan contribuido a afirmarla. El primero sedebeal esfuerzo deA Ifredo E. Mooney quien publicaun Tratado deDerecho Constitucional en cuatro tomos, dedicando el tomo cuarto en su totalidad al "Derecho Procesal Constitucional" (Ferreira Editores, Córdoba 1999). Más tarde, con algunos afinamientos se publica como volumen independiente: Derecho Procesal Constitucional, Ediciones de la Docta, Córdoba 2002 (la obra tiene un propósito descriptivo, acercándose a la posición de Sagüés y desarrollando la dogmática argentina).

Demayor envergadura es el esfuerzo realizado en un libro de cátedra con el título Elementos de Derecho Procesal Constitucional, Ed. Advocatus, Córdoba, tomol (2004) y tomo II (2005). En él escriben Carlos Hugo Valdez, Lorenzo Barone, Juan Fernando Brügge, José Daniel Godoy, Fernando M achado, María Elena Vidal, Javier A maya, Julieta Chalub Frau, Claudio Fernández, Natal ia González, Sandra E. Lalliya, Félix López Amaya, Martín Lucas, Víctor C. Rostagno y Ricardo Videla.

La parte doctrinaria está a cargo de José Daniel God oy que se extiende en un interesante desarrollo en el cual ubica al "derecho procesal constitucional" como parte del Derecho Constitucional ("Temas de Derecho Procesal Constitucional", tomo I, 9-138) tesis que no necesariamente comparten los demás co-autores. En lo quese refierea los procesos a cargo de esta disciplina, el libro incorpora los más conocidos y aceptados, pero incluye otros cuya ubicación no parece clara y en todo caso es discutible, como son el procedimiento para registrar la personeríajurídica de un partido político y el que se utiliza para obtener la naturalización y la carta de ciudadanía.

Lo anterior no agota la lista de lo existente, pero da una muestra bastante significativa de la importancia que tiene la disciplina en la Argentina, si bien, como es natural, al interior de ella no existe unidad en los planteamientos, sino más bien diversidad y contraposición entre ellos. Tampoco anotamos los numerosos libros dedicados al estudio de los instrumentos procesales como el A mparo, Habeas Data, Recurso Extraordinario, etc., cuyo análisis escapa al propósito de estas líneas o 
algunos autores que en los últimos años han realizado diversos abordajes sobre problemas tanto teóricos como prácticos (vid. María Mercedes Serra, Procesos y recursos constitucionales, Edic. Depalma, Buenos Aires 1992; Mario Masciotra y Enrique A. Carelli, director y coordinador, Derecho Procesal Constitucional, Edic. Ad-hoc, Buenos Aires 2006).

\section{EL CASO DE BRASIL}

La gran producción jurídica del Brasil no ha estado ajena a la problemática que nos ocupa, pero por motivos algo largos de explicar, no ha trascendido mayormente fuera de sus fronteras, no obstante su gran calidad, por lo que trataré de presentarla dela mejor manera y en forma concisa.

La primera vez que el término "derecho procesal constitucional" aparece en este país, es en la obra de un eminente procesalista José Frederico Marques, Instituiçoes de Direito Processual Civil,1ra edición, Editora Forense, Río de Janeiro 1958. En ella señal a estejurista la importancia quetienela Constitución para el resto del ordenamiento, al cual sirvedesoportey fundamento, agregando quesiemprequeun litigantese apoye en un precepto constitucional, existe un ejercicio por partedel Estado de una jurisdicción constitucional. Agrega queel control judicial de la constitucionalidad motiva que aparezca un "proceso constitucional", y de ahí que sea legítimo hablar de un "derecho procesal constitucional" para designar al conjunto de reglas destinadas a regular el proceso constitucional. Asi, en el derecho brasileño -acota- es objeto de un proceso constitucional toda pretensión que descansa en una regla emanada de la Constitución y no solo cuando se utilizan los expresos remedios constitucionales, como es el Habeas Corpus. Es por eso que nuestro autor considera que aislar todas esas normas de "derecho procesal constitucional" para construir una categoría científica, esto es, propia y diferenciada, le parece poco aconsejable y nada acertado. Por tanto, en la introducción del Derecho Procesal Civil y en la del Derecho Procesal Penal, es en donde deben incluirse todas las reglas respecto a los fundamentos jurídico-constitucionales de las normas del Derecho Procesal, y así el "derecho procesal constitucional" pasa a ser un capítul o propedéutico, si bien importante, dentro de cada uno dedichas ramas procesales(cit. tomo I, pp. 85-93; en la tercera edición de 1966 a cargo de la misma editorial en el tomo I, 84-85).

Por la mismaépoca repitesimilares conceptosen su obraEnsaio sobrea jurisdicâo voluntaria (Ed. Saraiva, 2da edición, Sâo Paulo 1959 pp. 25 ss.) en donde señala 
que el "derecho procesal constitucional" debe ser una condensación metodológica y sistemática de los principios introductorios del proceso en general.

Posteriormente, nuestro autor cambia su punto devista y asi lo vemos expuesto en una obra destinada a ser un condensado de sus aportaciones a la disciplina y que empieza a publicar desde 1974. Ella lleva como título el de Manual de Direito Processual Civil, y quetras su muerteserá actualizada por Ovidio Rocha Barros Sandoval (manejo la novena edición a cargo de Millenium Editora, Campinas 2003). En esta oportuni dad apunta una cierta desconfianza hacia lo que es el "derecho procesal constitucional" al que califica como conjunto de preceptos destinados a regular el ejercicio de la jurisdicción constitucional, o sea, la aplicación jurisdiccional de las normas de la Constitución en aras desu salvaguarda, pero a la quecon todo califica como una rama del Derecho Procesal. Pero agrega que esto no debe confundirse con el "derecho constitucional procesal" que trata de las normas procesales incorporadas a la Constitución (vol. I, pág. 4).

Es curioso advertir como el nombre y la inquietud de la disciplina ingresa al Brasil de manos de un procesalista queno solo seocupó del proceso civil, sino también y muy extensamentey con soltura del proceso penal, pero sin llegar a comprender del todo lo queexistía como proceso constitucional y deuna eventual disciplina que lo comprendiese. Y queaquí como en otros lugares, nos explica en al go los vaivenes que ella tuvo y tiene hasta ahora.

Posteriormente, Ia conocida procesalista italiana pero nacionalizada brasileña, Ada Pellegrini Grinover, publica una importante obra Os princípios constitucionais eo Código deProceso Civil, (Edit. J.Bushatsky, Sâo Paulo 1975) en donde vuelve a tocar el tema y lo considera como una condensación metodológica y sistemática de los principios constitucionales del proceso y que:" ...abarca, por un lado, la tutela jurisdiccional de los principios constitucionales de la organización judicial y del proceso, y por otro, la jurisdicción constitucional" (pág. 8). Se ve claramente que adopta un criterio que en el fondo no permite centrar el problema y tampoco lo concibe como disciplina autónoma. Este criterio será mantenido por la autora a través de su obra y tendrá gran influencia, como lo podremos apreciar más adelante.

Poco después y en línea similar, aparece la publicación de Roberto Rosas, Direito processual constitucional (principios constitucionais do proceso civil) Edit. Revista dos Tribunais, Sâo Paulo 1983, con reediciones, que es el primer 
libro que con ese título se publica en el Brasil. El autor señala que en las Constituciones hay muchas normas procesales y estas son la matriz que debe orientar todo proceso, para continuar con un desarrollo aplicable básicamente al proceso civil. Esto es, se aplica a los principios procesales que están en la Constitución y que deben orientar el proceso civil, y que es lo que denomina "Derecho Procesal Constitucional". Por el contrario, el "Derecho Constitucional Procesal" trata del proceso constitucional, o sea, de la legitimación procesal (pp. 1-2), que, por lo demás, lo comenta en forma tangencial.

Al año siguiente, se publica el importante libro de José Alfredo de Oliveira Baracho, Processo constitucional (Edit. Forense, Río de Janeiro 1984) quees un interesante aporte centrado en el proceso, si bien es un estudio global con un amplio soportecomparado en la legislación y doctrina extranjeras, que demuestra estar muy bien informado. A cepta la tesis deFix-Zamudio sobre la diferencia existente entre el "derecho procesal constitucional" y el "derecho constitucional procesal" (pp. 122 - 127) que muchos después seguirán en el Brasil. Según Baracho la condensación metodológica y sistemática de los principios constitucionales del proceso toma el nombre de "derecho procesal constitucional". No es rama autónoma, sino un enfoque metódico. El Derecho Procesal Constitucional analiza la tutela constitucional de los principios de la organización judicial, así como la jurisdicción constitucional, mientras que el Derecho Constitucional Procesal estudia los aspectos constitucionales del proceso. En todo caso, las líneas de diferencia que traza no son muy claras y tampoco se preocupa por buscar mayores sustentos teóricos, sino más bien expone lo existente premunido de un amplio respaldo doctrinario. Pero sin lugar a dudas este texto debe considerarse como el punto de partida para los posteriores estudios decarácter moderno queseharán en el Brasil, constituyendo desdeentonces un referente obligado de la disciplina.

No empece este inicio auspicioso, Oliveira Baracho cambió luego de opinión como parece desprenderse de un recienteensayo al quetitula como Teoría geral da justiça constitucional (en Fdo Luiz Ximenes Rocha y Filomeno Moraes, coordinadores, "Direito Constitucional Contemporâneo", Homenagem ao prof. Paulo Bonavides, Del Rey Edit., Belo Horizonte 2005). A quí hace suya la vieja distinción elaborada en 1928 por Charles Eisenmann que dice que la Justicia Constitucional es la especie a través de la cual se examinan las leyes inconstitucionales, mientras que la "jurisdicción constitucional" es el órgano a través del cual seejerce esetipo dejusticia. 
Poco después y antes de su fallecimiento, Oliveira Baracho publica su obra Direito Processual Constitucional (Edit. Forum, Belo Horizonte 2006) que constituye una importante y voluminosa compilación de ensayos publicados anteriormente, sobre el tema queanuncia el título así como aspectos afines. Se trata de un libro muy útil y documentado para compulsar trabajos escritos en diversas épocas reunidos por vez primera, pero queno representaningún avance sobre lo ya hecho. A lo que se agrega que ninguno consigna la fecha en la cual fue publicado originalmente, dificultando asi detectar la línea evolutiva de su pensamiento y sus variantes.

Marcus Orione Gonçalvez Correia (cf. Direito Processual Constitucional, Edit. Saravia, Sâo Paulo 1998, 1ra edición) partedel hecho dequeel Derecho Procesal Civil se asienta sobre las nociones de acción, proceso y jurisdicción. Y que lo anterior es básico para poder anal izar las normas procesal es que seencuentran en la Constitución, quepasan a ser una especiedesub-rama del Derecho quees el "derecho procesal constitucional", formado por normas de naturaleza procesal civil queseencuentran en la Constitución. O sea, el objeto del Derecho Procesal Constitucional lo constituye los principios de naturaleza procesal civil que están en la Constitución, que le permiten analizar de esta manera al gunos institutos queestán en la Constitución brasileña (mandato deseguridad, habeas corpus, etc.).

Pero en la segunda edición de la misma obra (Ed. Saraiva, Sâo Paulo 2002) considera otrosenfoquesy manteniendo su posición inicial, agrega queno puede desconocer un concepto "restringido" o "estrecho" sobre el "derecho procesal constitucional" que lo considera tan solo como un condensado metodológico, y reconoce la existencia de un "derecho procesal constitucional" al lado de un "derecho constitucional procesal" (pág. 2), pero por razones didácticas y de mejor uso expresa su preferencia por solo una de ellas, o sea, el "derecho procesal constitucional", de acuerdo a la configuración que le da. Sobre esa base, emprende una descripción somera de los procesos constitucionales contemplados por la Constitución brasileña de 1988, tal como lo hizo en la primera edición.

Interesante es la posición de André Ramos Tavares (cf. Tribunal e jurisdiçao constitucional, Celso Bastos editor, Sâo Paulo 1998) Su apartado 4.2 lo titula: "Jurisdicción constitucional: un problema terminológico". Y dice que las definiciones quesehan dado sobreella no gozan degeneral aceptación. Agrega luego que el Derecho Procesal Constitucional y el Derecho Constitucional Procesal son parcelas delajurisdicción constitucional: esto es, ambos derechos 
no son más que expresiones o desarrollos distintos de un solo punto de vista o enfoque, quesería la jurisdicción constitucional en sentido amplio (acepta pues la existencia tanto del Derecho Procesal Constitucional como del Derecho Constitucional Procesal).

Más adelante, replantea y matiza su tesis inicial, como lo expresa en un libro formidable: Teoria da justiça constitucional, Edit. Saraiva, Sâo Paulo 2005. La obra trata exhaustivamente los siguientes temas: Estado de Derecho y Justicia Constitucional, categorías fundamentales, morfología del Tribunal Constitucional y proceso decisorio, legitimidad del Tribunal Constitucional y sus diversas concepciones.

La "justicia constitucional", tal como ahora lo entiende Tavares, se presenta como una disciplina jurídica autónoma, quetienedos maneras de manifestarse: el Derecho Procesal Constitucional (estudia y analiza el proceso objetivo) y el Derecho Constitucional Procesal (analiza los aspectos constitucionales que tratan sobre el proceso). La obra por lo demás, más que desarrollar estos conceptos, está destinada al análisis de sus fundamentos doctrinarios, que lleva a cabo con gran agudeza.

Distinta es la posición de Willis Santiago Guerra Filho (cf. Processo Constitucional e Direitos Fundamentais, Celso Bastos editor, Sâo Paulo 1999 e Introduçâo ao Direito Processual Constitucional, Sintese editora, Porto Alegre 1999). El autor señala que su objetivo es abordar la dimensión constitucional en donde se sitúan los institutos jurídicos protectores (mandato de seguridad, mandato deinjunción, etc.) en la medida quedefienden derechos fundamentales, etc. Esta disciplina denominada "derecho procesal constitucional" no tiene aun afirmada su autonomía científica, pero es una posición que busca extraer de la Constitución las normas del proceso. En tal sentido, su objetivo es tan amplio, que desborda a cual esquiera existenterama procesal y en consecuencia sus temas típicos son la organización de la estructura judicial, la competencia entre sus órganos, los princi pios generales del proceso, entreotros, algunos de los cuales son los que estudia con detalle (sobre todo en la segunda obra mencionada, parte primera). Agrega, por otra parte, que la nueva disciplina debeestar cerca de la Teoría General del Proceso, la que podría incluso absorber en gran parte a aquélla, con lo cual podría perder su cercanía con el Derecho Constitucional. En nota a pie de página se refiere a la distinción popularizada en el Brasil, al parecer por Roberto Rosas, entre "derecho procesal constitucional" / "derecho constitucional procesal", que le parece superflua. Y 
esto probablemente porquesu postura es englobante y total, al extremo queno Ilega a precisar el planteo que defiende, si bien haceun amplio desarrollo delos temas quesepropone.

Marcelo Cattoni (cf. Direito Processual Constitucional, Mandamentos Edit., Belo Horizonte 2001) presenta una obra precedida por una extensa fundamentación de corte filosófico de sumo interés. Señala que todo proceso debe ser constitucional no solo por su adecuación a la Constitución, sino porque todo órgano judicial es competente para apreciar cuestiones constitucionales. Detal manera, la distinción entre Derecho Procesal Constitucional/ Derecho Constitucional Procesal cae por su base, deviene superflua y pierde sentido, aun cuando tenga su historia (pp. 206-213). Agrega, además, que esta dupla es problemática, señalando queexisteevidentementeuna conexión entreel proceso y la Constitución en cuya fundamentación se extiende con detalle. Pero su preferencia apunta a lo que da el título a la obra.

Un constitucionalista de fuste y que puede considerarse un clásico es Paulo Bonavides, con una amplia como sólida obra, quelo col ocan en un lugar relevante dentro dela producción jurídica brasileña. Sin embargo, no ha desarrollado la temática que nos ocupa, aun cuando al pasar ha dejado un apunte que lamentablemente no ha logrado desarrollar. Así, en su magnífico Curso de Direito Constitucional (Malheiros editores, 13ava edic., Sâo Paulo 2003, pág. 46) dice que con la publicización del proceso por obra de las doctrinas procesales, los lazos entreel Derecho Constitucional y el Derecho Procesal son tan íntimos, que de esa unión parece nacer una nueva disciplina en gestación, que es el "derecho procesal constitucional". Interesantísimo aserto que ha quedado sin desarrollar.

Ivo Dantas ha emprendido una obra de largo aliento sobre el tema que nos ocupa en una importante obra, de la que hasta ahora solo ha publicado el primer tomo: Constituiçao eProcesso, vol. I. Introduçao ao Direito Processual Constitucional, Juruá editora, Curitiba 2003. Señala que el pionero de los modernos estudios en materia de jurisdicción constitucional en el Brasil es Oliveira Baracho-como ya lo he señalado-y luego de un largo recorrido doctrinario que demuestra estar muy bien documentado, dice que existen dos disciplinas: el Derecho Procesal Constitucional y el Derecho Constitucional Procesal. Su posición (pág. 132) la desarrolla al señalar que la diferencia entre ambas posturas, o sea, entre ambas disciplinas, es deorden epistemológico y en consecuencia está marcada por juicios de valor. Con todo, adelanta que el 
Derecho Procesal Constitucional abarca normas, en especial el proceso constitucional y sus temas son los de la jurisdicción constitucional. Mientras que el "derecho constitucional procesal" estudia las normas procesales de la Constitución. En otras palabras:

a. Derecho Procesal Constitucional: jurisdicción constitucional y control de constitucionalidad, así como jurisdicción de las libertades, o sea, defensa dela Constitución y de las personas,

b. Derecho Constitucional Procesal: estudia las garantías referentes al proceso y al procedimiento: dueprocess of law.

Pero a estas dos disciplinas, que las considera válidas, agrega una tercera:

c. Derecho Constitucional Judicial: estudia el Poder Judicial, el Ministerio Público y la abogacía.

Finalmente, señala que el Derecho Procesal Constitucional y el Derecho Constitucional Procesal se encuentran, ambos, más vinculados al Derecho Constitucional queal Derecho Procesal.

Paulo Roberto de Gouvêa Medina es autor de un valioso texto dedicado a la disciplina: Direito processual constitucional, Editora Forense, 1ra. edición, Río de Janeiro 2003. Dice que el Derecho Procesal Constitucional tiene por objeto sistematizar las normas y principios de la Constitución concernientes al proceso, y más que una rama del Derecho Procesal es un método de estudio, pero que puedeincorporarseala Teoría General del Proceso. Señal a queal gunos separan el Derecho Procesal Constitucional en dos partes; la segunda sería el Derecho Constitucional Procesal y que tendría por objeto de estudio los principios e instituciones constitucionales del proceso, correspondiendo a la primera la jurisdicción constitucional, o sea, los procesos constitucionales. Pero esta distinción la rechaza, pues dice que no tiene bases metod ológicas seguras. Añad equeel nombreno es importante, pero que no se puededividir el estudio de un solo tema en dos parcel as distintas. A demás, como todo es constitucional, podríamos crear infinidad de disciplinas sobre la base de lo que hay en la Constitución, lo quees preferibleevitar. N o obstante, tratándose dela función jurisdiccional quees sumamenteimportanteen la vida del Estado moderno, se justifica ampliamente la existencia de un "derecho procesal constitucional", queen rigor es lo que hay que mantener. 
El libro se ocupa además de la jurisdicción (control de la constitucionalidad y defensa del os derechosfundamentales) y del Poder Judicial. La misma línea de pensamiento se advierte en las ediciones posteriores que se han sucedido con rapidez (2da edición, 2003 y 3ra edición 2005).

Gustavo Rabay Guerra (Direito Processual Constitucional, Nossa Livraría, Recife 2005) parte resal tando la importancia del proceso y señala que hay una creciente constitucionalización del proceso, es decir, cada vez más las constituciones contienen principios procesales, siendo así que el "derecho procesal constitucional" es el estudio de los principios procesales que se encuentran en la Constitución, o sea, es el que analiza la dimensión constitucional del proceso, creándose así el debido proceso. Con estepunto de partida, se dedica a analizar los principios procesales aplicables al proceso civil (pp. 23-28).

Finalmentehay quemencionar el manual dePaulo $\mathrm{H}$ amilton SiqueiraJr. Direito processual constitucional, Editora Saraiva, Sâo Paulo 2006. Intenta su autor ofrecer una panorámica dela disciplina quees reciente, pero que cada vez goza de mayor aceptación en el Brasil, a la cual ubica como una rama nueva del Derecho Procesal. El Derecho Procesal Constitucional tiene, según indica, tres capítulos: a) el control dela constitucional idad o jurisdicción constitucional, b) los writs o procesos constitucionales, esto es, la jurisdicción constitucional dela libertad, y c) la defensa de la ciudadanía o jurisdicción constitucional política, que en el Brasil son la acción civil pública y la acción popular. Agrega luego que el "Derecho Constitucional Procesal" es un capítulo del Derecho Constitucional y de la Teoría General del Proceso, es decir, no es autónomo con respecto a las demás disciplinas.

Más adelante (pág. 37 ss.) precisa que para graficar la relación de reciprocidad entre el Derecho Procesal y el Derecho Constitucional podemos utilizar dos denominaciones: "derecho constitucional procesal" y "derecho procesal constitucional" pero la convivencia de las dos puede conducir a que tengan un solo nombre: "derecho constitucional procesal". Sin embargo, podemos distinguir a su interior entre el "derecho constitucional procesal" (elenco de principios procesales consagrados en la Constitución) y el "derecho procesal constitucional" (que tiende a regular la jurisdicción constitucional, o sea, el habeas corpus, el habeas data, etc.). Este último es autónomo y es rama del Derecho Procesal. 
La sucinta enumeración de las obras existentes en el Brasil con el título de "derecho procesal constitucional" no agota lo existente. El tema además es tratado por numerosos especialistas en ensayos dispersos (como es el caso notable de J oséA fonso Da Silva y posteriormente de Gilmar Ferreira M endes y Ruy Sammuel Espíndola) tanto en libros sobretemas generales como en ensayos publicados en revistas especializadas. Y por cierto, por un número apreciable de procesalistas, que dan cuenta de la disciplina desde distintos puntos de vista y en libros dedicados a temas generales o específicos como el control de constitucionalidad. Así, Antonio Carlos de Araújo Cintra, Ada Pellegrini Grinover y Cândido Rangel Dinamarco en su muy difundida Teoría Geral do Proceso, M al heiros editores, 22a edición, Sâo Paulo 2006, dedican el capítulo 5 de su obra al "direito processual constitucional" (pp. 84-93). Esta disciplina es concebida como "condensación metodológica y sistemática de los principios constitucionales del proceso" y no constituye una rama autónoma del Derecho Procesal sino una colocación científica, un punto de vista metodológico y sistemático desde el cual se puede observar el proceso y sus relaciones con la Constitución. Comprende, por un Iado, a) la tutela constitucional de los principios fundamental es de la organización judicial y del proceso, y por otro, b) Ia jurisdicción constitucional. Esta última es entendida como aquella que comprendeel control judicial dela constitucionalidad delas leyes, así como los remedios constitucionales como el Habeas Corpus, el Mandato de Seguridad, etc. Y al go similar encontramos en la val iosa obra de oséFrederico Marques, ya mencionada.

De lo anteriormente expuesto puede desprenderseque la comunidad jurídica brasileña conoció y aceptó desde época muy temprana el concepto de "derecho procesal constitucional". Primero por parte de los procesalistas y luego de los constitucionalistas, encontrándose ambos presentes en el debate delosúltimos años. En efecto, el término asoma por vez primera en 1958 y ha tenido una suerte muy variada desdeentonces, beneficiándosedegran cantidad delibros dedicados a ello, que muchas veces se destinan a cursos especializados o específicamente dedicados al tema, y que además gozan del favor de los lectores, como puede verse en algunos que han alcanzado varias ediciones. Lo cual demuestra el interés y el vigor que ha encontrado en ese país, que es quizá el que desdeel punto de vista de la cantidad, más ha publicado sobre esta disciplina.

En contraste con esto, las opiniones o enfoques dados a conocer son de los más variados y en cierto sentido contradictorios, pues existeal interior de la 
doctrina varios enfoques no necesariamente coincidentes entre sí, pues en sus extremos se niega incluso la posibilidad de que el Derecho Procesal Constitucional sea una disciplina jurídica, sino tan solo un enfoquedidáctico y metodológico.

Pero por otra parte, esta exuberancia creativa tienesus aspectos positivos, pues del diálogo y de la discusión pueden salir nuevas ideas y muchos avances. Pero para eso es quizá necesario quesus cultores se junten a reflexionar sobrelo que es el tema de estudio, a fin de encontrar puntos en común que permitan consensos y mayores avances, que vayan perfilando las diferentes tesis y diferencias que todavía se ven ahora.

\section{EL CONTROL CONSTITUCIONALEN FRANCIA}

Los años veinte del siglo pasado son una clara muestra del fermento de las ideas del control constitucional en Francia, en gran parte originado por la influencia constitucional norteamericana (del que se contaba con un ejemplar model o en la clásica obra deA lexis de Tocqueville, La democracia en A mérica, 1835-1841).

El punto de arranque probablemente lo tenemos en la obra, polémica, de Edouard Lambert, Le gouvernement des juges quees de 1921(y de la que hay traducción italiana). Luego siguen otros trabajos sueltos, libros como el de Ch.Eisenmann (que fue su tesis doctoral avalada con prólogo de Kelsen) y sobre todo el número especial queal tema dedica la Revue de Droit Public et dela Science Politiqueen 1928 (tomo 45) en aquella época dirigida por G. Jéze y en la cual publican ensayos H.Kelsen, el mismo Eisenmann, MirkineGuetzevich, Marcel Waline, entreotros. Así como el M élanges dedicado a M. Hauriou (en 1929) y los textos de los autores clásicos dela escuela francesa, L. Duguit y M.Hauriou.

Pero es importante señalar que lo que se usa es el concepto de "jurisdicción constitucional" con la excepción de Ch.Eisemann que se inclina por el de "justicia constitucional", ya que el texto de Kelsen, publicado en francés en 1928, si bien utiliza el de "justicia constitucional" en el título, en el resto del ensayo emplea ambos conceptos en forma indistinta y sin diferenciarlos. Con el agravante de que esa licencia se la tomó Eisenmann, traductor del texto kelseniano, en cuyo original alemán se utiliza la voz "jurisdicción", como lo he señalado en otra oportunidad. 
Pese a tan buenos augurios que señalaban la necesidad de un control jurisdiccional y no solo un control político como existía entonces, la idea va a cuajar muy lentamente y solo se concreta con la creación del Consejo Constitucional en 1958 y su posterior funcionami ento y avancejurisprudencial, en especial a partir de 1971.

Sin embargo, el tema sigue siendo de atención preferente de los constitucionalistas, como se acredita con una rápida revisión de los manuales en circulación (J. Cadart, M. Duverger, P. Ardant, M. Prélot, G. Burdeau,J. Gicquel, A. Hauriou, P. Pactet, F.H amon y M.Troper, etc.)

Y siempre con el uso de "justicia constitucional" de modo recurrente. Es solo el manual dirigido por Louis Favoreu el que intenta una fundamentación de la "justicia constitucional" y el que emplea, muy al pasar, el concepto "derecho procesal constitucional" (cf. L. Favoreu et alter, Droit Constitutionnel, $8^{\circ}$ ed., Dalloz, Paris 2005, p. 238; la primera edición es de 1998).

Sin embargo, existela tendencia en aceptar dequelo quesedesarrolla al interior de un contencioso queselleva anteel Consejo Constitucional es en real idad un proceso, y así lo reconocen algunos que incluso pretenden llegar más allá en punto a teorizaciones (cf. Pascal Jan, Le procès constitutionnel L.G.D. J., Paris 2001).

No obstante, Francia al igual que Ital ia prácticamenteignora el término, con la ventaja para I tal ia de queen este país ha habido un debate, que a veces renace, sobrelas implicancias teóricas y procesales del control constitucional, queestán casi ausentes en Francia.

\section{ESPAÑA Y EL DERECHO PROCESAL CONSTITUCIONAL. Nota sobre Portugal}

Como importanteavanceteniendo presenteel momento en el cual fueelaborado, debemencionarsela ponencia del procesalista español JaimeGuasp, La justicia constitucional en España, quepresenta al Primer Congreso M exicano deDerecho Procesal en M éxico en 1960, y quese reproduceen ese país (aquí lo tomamos de la siguiente publicación: "Boletín del Colegio de Abogados de Guatemala", núms. 5-6, 1960). Señala Guasp queestamos ante un proceso, que se enrola en el ámbito del Derecho Procesal y quelo mejor para su desarrollo es la existencia deun tribunal específico, como lo fueel Tribunal de Garantías Constitucionales español de 1931. 
Pero el que primero emplea, concientemente, el término "derecho procesal constitucional" es José Almagro Nosete en su artículo Tres breves notas sobre Derecho Procesal Constitucional publicado en la "Revista de Derecho Procesal Iberoamericana", núm. 3-4,1979. Aquí acepta la distinción entre "Derecho Procesal Constitucional" y "Derecho Constitucional Procesal" señalando que el Derecho Procesal Constitucional sedistinguepor la peculiaridad desu objeto, pues cuando el objeto versa sobre Derecho Constitucional, el objeto es constitucional. Admite que si bien Kelsen es el fundador de la disciplina, es Calamandrei quien pone sus bases. Y luego esboza un programa tentativo de su contenido quesería así: primera parte: jurisdicción constitucional, segunda parte: el derecho a la jurisdicción constitucional y tercera parte, el proceso constitucional.

Complementan este ensayo otros de temas afines como son los siguientes: Un precursor en España del moderno Derecho Procesal Constitucional en "Revista de Derecho Procesal Iberoamericana", núm. 1,1981(en donde rescata la obra de Jorge A. Alvarado, titulada "El recurso contra la inconstitucionalidad de las leyes" de 1920, quien habla de un "derecho procesal constituyente") y El derecho procesal en la nueva Constitución, "Revista de Derecho Procesal Iberoamericana", núm. 4,1978 .Ambos han sido reunidos posteriormente, conjuntamentecon otros textos en su libro Constitución y proceso, Lib. Bosch, Barcelona 1984.

Casi de inmediato, Almagro Nosete publica un amplio comentario sobre el nuevo Tribunal Constitucional y su reglamentación con el siguiente título: Justicia Constitucional, Madrid 1980 y más adelante desarrolla el tema en un trabajo de espectro más amplio: Lecciones de Derecho Procesal (laboral, contencioso-administrativo, constitucional) con la colaboración de Pablo Saavedra Gallo, 2da. Edic. Tirant Le Blanch, Valencia 1991.

Por la misma época, Nicolás Gonzáles-Deleito Domingo publica Tribunales Constitucionales. Organización y Funcionamiento, Edit. Tecnos, M adrid 1980 en donde parte de una breve noticia del "derecho procesal constitucional" como proemio a su estudio comparado, disciplina que considera de carácter procesal.

Pero correspondea Jesús González Pérez el mérito dela publicación del primer libro con esetítulo: Derecho Procesal Constitucional, Edit. Civitas, Madrid 1980 que es un comentario doctrinario de la nueva ley orgánica del Tribunal 
Constitucional deEspaña, con abundanteinformación. El autor tieneun enfoque netamente procesal, dice que el "derecho procesal constitucional" es un conjunto denormasqueregulan el proceso constitucional y añadequeno hay jurisdicción constitucional sino desde 1920, con la creación de la Corte Constitucional austriaca, ya que el proceso constitucional es precisamente el que conoce un tribunal constitucional. De esta suerte, el llamado "control difuso" por la doctrina, no encaja dentro deuna jurisdicción constitucional, ya queno existen órganos ad-hoc para conocerlos.

Con posterioridad estos enfoques son abandonados, aun cuando se empleen, como hemos vistos, en el título de algunas obras (cf. Víctor Fairén Guillén, Estudios de Derecho Procesal Civil, Penal y Constitucional, Edersa, M adrid, 3 tomos, 1983-1992). O cuando al gunos lo tratan con cierto detenimiento dentro de una obra con otros alcances (así, Raúl Bocanegra Sierra, El valor de las sentencias del Tribunal Constitucional, IEA L, Madrid 1982, donde discute el concepto de "derecho procesal constitucional" en la doctrina alemana, pp. 161-171). Y otros estudiosos que hacen amplia referencia a ella, como es el caso dejoséJulio Fernández Rodríguez (cf. Lajusticia constitucional europea anteel siglo XXI, Edit.Tecnos, Madrid 2002).

En España, por lo demás, existeuna producción extensa y muy valiosa en torno a lajurisdicción o justicia constitucional-nombrequees preferido por el grueso de la doctrina-acorde con la actividad de su Tribunal Constitucional y la experiencia europea que tienen a la mano, enfocada de manera preferente, por constitucionalistas. Pero sin hacer mayores referencias al problema de fundamentos o ubicación de la temática, no empece que hay análisis sobre aspectos y situaciones procesales de gran alcance, y como reitero, abundantísimos.

Mención especial merece Francisco Fernández Segado, autor de una extensísima obra, dedicada al Derecho Constitucional y también al Derecho Militar, quien es el constitucionalista español más dedicado y más autorizado sobre el constitucionalismo latinoamericano. Desde temprano Fernández Segado se dedicó a estos temas (cf. su libro La jurisdicción constitucional en España, Ed. Dykinson, Madrid 1984) y ha escrito largamente sobre ellos (aun cuando sin tocar el concepto de "derecho procesal constitucional") habiendo demostrado gran perspicacia y originalidad en sus enfoques, de los cuales señalo únicamente dos: la evolución de la jurisdicción constitucional en la A mérica Latina y la superación de los model os clásicos existentes en Occidente, 
y sobre los que ha publicado vastamente, en textos que además han sido traducidos al italiano y al francés. Me limito a citar los siguientes: La jurisdicción constitucional en A mérica Latina, Ingranusi Ltda., M ontevideo 2000; Del control político al control jurisdiccional. Evolución y aportes a la justicia constitucional en América Latina en "Anuario de Derecho Constitucional Latinoamericano", año 12, 2006, tomo I y La justicia constitucional ante el siglo XXI:la progresiva convergencia de los sistemas americano y europeo-kelseniano, U NAM , M éxico 2004,con justiciero prólogo de Héctor Fix-Zamudio. Fernández Segado dirige además desde M adrid, el "Anuario Iberoamericano de Justicia Constitucional", que ha dado amplia cabida a las inquietudes latinoamericanas sobre el tema, sin ningún tipo de exclusiones.

En forma marginal, un jurista dela nueva generación, Joaquín BrageCamazano, ha tocado el tema y ha hecho contribuciones de primer orden en cuanto a procesos constitucionales se refierey con agudas incursiones en la problemática constitucional de América Latina; entre otros, cf. La acción abstracta de inconstitucionalidad, UNAM, México 2005.

Al igual queEspaña, Portugal ha tenido una historia política al go agitada en el siglo XX: Iargas dictaduras autoritarias de corte corporativo y luego una transición política interesante, pero con peculiaridades. En el caso de España eso significó una vuelta o restauración de la monarquía, lo que no sucedió en Portugal. A mbos países retornaron a la democracia a mediados de los setenta del siglo pasado, con nuevas constituciones, más democrática la española, como años después lo sería la portuguesa con los cambios introducidos, que incluían la figura del Tribunal Constitucional.

En Portugal se han dado igual mente una gran cantidad de estudios sobre lo que en términos generales se conoce como "jurisdicción constitucional" y ella figura, sobretodo, en los textos más acreditados de la disciplina constitucional (como pueden ser los de Joséjoaquin Gomes Canotilhoy Jorge M iranda).

Pero el concepto "derecho procesal constitucional" no ha tenido ingreso en el uso de la comunidad jurídica. De excepción es el Breviário de Direito Processual Constitucional (Recurso de Constitucionalidade) de Guilherme da Fonseca e Inés Domingos, Coimbra editora,2da edición 2002;la primera edición es de 1997 en la misma editorial ,análisis más bien puntual de un determinado proceso. 


\section{EL INTERESANTE PANORAMA ITALIANO}

Como lo he señalado con anterioridad, el caso de Italia presenta un desarrollo muy peculiar, y con perspectivas de gran riqueza doctrinaria que se refleja en una literatura inmensa, cuyo conocimiento es prácticamente imposible de al canzar. Deahí que deba limitarmea destacar tan solo los aspectos más sal tantes deesta riquísima doctrina y en la medida que toqueel concepto o tópico que nos interesa. Así vemos quedespierta interésen los procesalistas desdemuy temprano, motivado por la introducción de la Corte Constitucional establecida en la Constitución de 1947, puesta en vigor en 1948, y cuya primera sentencia se dará tan solo en 1956. Y reforzado por el hecho de que a diferencia del Estatuto Albertino, la nueva Constitución es rígida, e incluso con algunos contenidos pétreos. Sin embargo, aun antes de funcionar la Corte y desde 1950, con motivo del Congreso Internacional de Derecho Procesal Civil (Florencia, 30 desetiembre3 de octubre de 1950) se plantea el problema, y del mismo año son varios los trabajos en torno a estos temas. Y todo fruto dela inqui etud delos procesalistas, que no obstante ello no aciertan en satisfacer todas sus inquietudes (en dicho Congreso seocupó dela parteprocesal delanueva Constitución, Virgilio Andrioli eintervino, con ideas no muy claras, el eminenteCarnelutti; cf. Atti del Congresso Internazionale di Diritto Processuale Civile, CEDAM , Padova 1953).

Pero en cierto sentido las bases del debate las pone Piero Calamandrei con el ensayo: La ilegitimidad constitucional delas leyes en el proceso civil, de 1950, al quesiguen otros intentos. De ellos el más notable es Mauro Cappelletti, que inicia la publicación de una serie de ensayos de largo aliento sobre la materia, que tienen su punto de partida en su conocida monografía de 1955: La giurisdizione costituzional e delle libertà. Y en otra que al canzó gran difusión: Il controllo giudiziario di costituzionalità delle leggi nel diritto comparato, Giuffré editore, Milano 1968 (ambas con reimpresiones).

Sin embargo, se tiende a denominar como "jurisdicción constitucional" a la disciplina o tópico que estudia la materia de estudio. Y así será durante muchos años hasta la actualidad, en donde parece predominar el uso, bastante generalizado, de "justicia constitucional".

En el ensayo pionero de Cappelletti seutiliza, como queda dicho, el membrete de "jurisdicción constitucional". Pero en sus textos publicados o difundidos en el mundo sajón, en especial en los Estados Unidos, utiliza el de "judicial review" propio de aquel país. Y en sus textos en francés, se inclina por el de "justice 
constitutionelle". Cappelletti parece, pues, no estar interesado por los nombres aun cuando ellos a la larga denoten algo más que una etiqueta.

N o obstante, cabe Ilamar la atención que en alguna oportunidad Cappelletti utiliza el concepto de "derecho procesal constitucional" con todas sus letras y lo hace en el ensayo "Il significato del controllo giudiziario di costituzionalità delle leggi nel mondo contemporaneo" de 1968, incluido en su libro Processo e ideologie (II Mulino, Bologna 1969, pág. 493). Pero lo hace al pasar, sin mayor afinamiento y sobre el cual no ha vuelto.

Llamativo es el ensayo de Renzo Provinciali, Norme di Diritto processuale nella Costituzione en la "Rivista Trimestrale di Diritto e Procedura Civile", núm. 2,1959, en donde su autor, profesor ordinario de Derecho Procesal de la Universidad deParma utiliza, quizá por vez primera en Ital ia, I os conceptos de "derecho procesal constitucional" y de "derecho constitucional procesal". El primero comprende los principios e institutos constitucionales del Derecho Procesal. Y el segundo, o sea, el Derecho Constitucional Procesal, trata de los procesos constitucionales. El autor tiene presente diversas contribuciones de Calamandrei y sobretodo deEduardo J.Couture, a quien cita detenidamente. $Y$ con este binomio, al que da un significado especial, seadelantará a un uso que tendrá mucha aceptación en A mérica Latina a partir de la década del setenta del siglo pasado.

Otra referencia la encontramos en A lessandro Pizzorusso (Lecciones de Derecho Constitucional, CEC, Madrid 1984, tomo I, pp. 10-11; la edición en italiano es de 1984) en donde lo toma como equivalente al de "justicia constitucional". Años mástardevuelvesobreel tema en su texto Uso ed abuso del Diritto processuale costituzionale en "Perspectivas Constitucionais" (Nos 20 años de Constituiçao de 1976, Jorge M iranda, coordinador, vol. I, Coimbra Editora 1996) en donde toca en general la actividad de la Corte Constitucional sin tomar una posición sobre el concepto que utiliza para titular su ensayo. Con posterioridad no ha vuel to sobre el tema, aun cuando ha hecho referencia a la Corte Constitucional y a su actividad dentro de la última edición de su Manuale di Istituzioni di Diritto Pubblico, Joveneeditore, N apoli 1997 y en ensayos dispersos (cf. Justicia, Constitución y Pluralismo, Palestra Editores, Lima 2005).

Una posición vinculada con la actividad de la Corte Constitucional la encontramos en Massimo Luciani, Le decisioni processuali e la logica del giudizio costituzionale incidentale, CEDAM, Padova 1984, quien hace 
referencia al "derecho procesal constitucional" pero al pasar y usando al mismo tiempo el de "justicia constitucional".

Por su lado, Gustavo Zagrebelsky iba a dedicar un tratamiento extenso a la voz processo constituzionale en la "Enciclopedia del Diritto", tomo XXXVI, 1987 (con separata de 1989) y que va a tener una gran influencia en los estudios posteriores.

De singular importancia es el Seminario Ilevado a cabo en Roma en la sede de la Corte Constitucional, sobre el tema Giudizio "a quo" e promovimento del processo costituzionale durante los días 13y 14 de noviembre de 1989 y cuyas actas serán editadas en 1990 por la editora Giuffréy bajo el mismo título. En ese evento hubo importantes contribuciones y secontó con la presencia, entreotros, de Paolo Barile, Giuseppe Abbamonte, Mauro Cappelletti, Augusto Cerri, Leopoldo Elia, TemistodeM Martines, Carlos Mezzanote(quetieneun interesante aproximación al tema), Livio Paladin, Alessandro Pizzorusso, Roberto Romboli, Gustavo Zagrebelsky, etc. Si bien setrataron en esa oportunidad problemas de todo orden, más bien vinculados con la problemática italiana, es de señalar el hecho dequeahí aprovechó Zagrebelsky, magistrado y mástardePresidente de la Corte Constitucional, para plantear la posibilidad y la necesidad de una disciplina denominada "derecho procesal constitucional". El planteo de Zagrebelsky sin lugar a dudas es sugestivo y da un avance en un medio algo escéptico, pero debetomarsecomo un punto departida, quelamentablemente no ha continuado (su intervención Diritto processualecostituzionale? seincluye en AA.VV. "Giudizio a quo e promovimento del processo costituzionale", Giuffré, Milano 1990, hay traducción castellana de esteensayo, no así del resto delas intervenciones en el Seminario).

Un estudio de largo aliento con importantes reflexiones y sobre todo con sugerencias en torno a las relaciones de nuestra materia con la teoría procesal, lo vemos en el meditado texto de Marilisa D 'A mico, Dalla giustizia costituzionale al diritto processuale costituzionale: spunti introduttivi (en "Giurisprudenza italiana", IV, 1990) que lamentablemente no ha despertado seguimientos. Como tal ha sido reproducido como capitulo primero del libro de la autora Parti e processo nel la giustizia costituzionale, G. Giappichelli editore, Torino 1991, pp. 11-57.

En losúltimosaños seha dedicado al tema con rara intensidad Roberto Romboli, organizador de varios eventos y sobre todo animador del denominado "Gruppo 
de Pisa" (un grupo de 350 estudiosos que se reúnen periódicamente) que ha publicado una valiosa serie editorial bajo el nombre común deAggiornamenti in tema di processo costituzionale y que cubre los siguientes periodos hasta ahora: 1987-1989; 1990-1992; 1993-1995; 1996-1998; 1999-2001; 20022004, dedicado cada uno de ellos al debate sobre las actividades de la Corte Constitucional, pero sin desarrollar el tema del "derecho procesal constitucional" tocado de soslayo en algunos de los volúmenes de esos periodos.Romboli es conciente de la existencia de un "proceso constitucional" e incluso ha planteado la posibilidad de un "derecho procesal constitucional viviente", aserto sobre el cual,sin embargo,no ha retornado(cf. R. Romboli, Premessa en "Il Foro Italiano", La Corte Costituzionale: profili processuali e istituzionali, a cura di...varios autores, Roma 2000) No obstante y a fin de unificar sus planteos sobreel sistema italiano de control constitucional, Romboli ha publicado recientemente con Elena Malfatti y Saulle Panizza, un manual titulado Giustizia costituzionale (Giappichelli editore, Torino 2003). Romboli es en la actualidad el más representativo y quizá el más destacado de los estudiosos italianos en el tema quenos ocupa.

A parte de los manuales de Derecho Público o de Derecho Constitucional que incluyen siempre un apartado dedicado a la "justicia constitucional" o a la "Corte Constitucional", existen libros dedicados exclusivamente a la "justicia constitucional", como los de Federico Sorrentino, Stefano Cicconetti, Virgilio Andrioli, Augusto Cerri, Giancarlo Rolla, etc. E incluso numerosos libros colectivos que publican las ponencias y debates de los frecuentes eventos dedicados al análisis de los aspectos puntuales de la "justicia constitucional" (entre otros puede verse La giustizia costituzionale ed i suoi utenti que recoge las ponencias presentadas a un encuentro internacional en honor del prof. V. Onida y a cargo de Pasqual e Pasquino y Barbara Randazzo. Ha sido publicado por Giuffréeditoreen 2006, y si bien tieneintervenciones de sumo interés, el carácter internacional dado al convenio es más una sana intención que una realidad).

Al lado de ellos hay que destacar el de Gustavo Zagrebelsky (La giustizia costituzionale, II Mulino, 1ra edición de 1977; la 2da. muy ampliada y prácticamente nueva con respecto a la anterior es de 1988, con reimpresión en 1989) que en realidad es un pequeño tratado de alto nivel que es uno de los mejores en su género y referente obligado en el tema aun cuando muestra más simpatía por el enfoquegeneralmente usado por la comunidad italiana. 
Existen también trabajos y monografías sobre aspectos diversos de la problemática que hacen referencia al "derecho procesal constitucional", en forma clara pero sin mayores desarrollos (cf. Tania Groppi, I poteri istrutori della Corte Costituzional enel giudizio sulle leggi, Giuffré, Milano 1997).

Lucio Pegoraro tieneun breve pero interesanteanálisis en Lineamenti di giustizia costituzional e comparata, G.Giappichelli, Torino 1998 en donde toca el tema al inicio, pero va más al enfoque comparado, que pocos han hecho en Italia.

Un sugestivo enfoque teórico, si bien breve, es el que hace Jorg Lüther (I dee e storie di giustizia costituzionale nell' ottocento, Giappichelli Ed. Torino 1990, cap. primero) quien precisa como datos a tener en cuenta el objeto y el método del "derecho procesal constitucional", sobre el cual hay dos enfoques, el "procesalista" y el "constitucionalista" sin llegar a tomar una postura sobre el tema y con simpatías hacia un enfoque mixto.

Por otro lado, A ntonio Ruggeri y A ntonio Spadaro han publicado un exitoso Lineamenti di Giustizia Costituzionale(G.Giappichelli editore,2da edición,Torino 2001)quese inicia con un interesanteexcursus teórico que refleja en algo la situación actual de la academia italiana.Dicen los autores que la "justicia constitucional" o lo que es lo mismo el "derecho procesal constitucional" es una rama del Derecho Constitucional, pues ambas están tan íntimamente ligados, que es muy difícil pensar que anden separados. El mismo criterio lo repiten en la tercera edición que es de 2004, si bien la obra ha quedado aligerada en lo referente a notas y ampliaciones que eran tan atractivas en las ediciones anteriores. Pero que lo hacen muy útil en los círculos universitarios.

La inmensa variedad de enfoques existentes en la doctrina italiana-de la que aquí nos hemos limitado a dar una referencia muy esquemática-confirma que en la actualidad la actividad de la CorteConstitucional es el tema preferido de los juristas italianos y que esto atrae sobre todo a los constitucional istas, y no siempre a los procesalistas. Lo cual explica que el enfoque procesal no tenga hoy en día mayor relevancia, no obstante que la disciplina procesal en Italia tieneun altísimo nivel académico.

Igualmente en el campo curricular, lo que existe son cursos de "justicia constitucional" motivo por el cual es de suponer que esto sea lo que prevalezca en el futuro (un panorama con el análisis de lo principales problemas que 
conlleva esta disciplina, vid. Marilisa D'Amico, Parti e processo nella giustizia costituzionale, cit.)

Los procesalistas, como ya heindicado, se han desentendido prácticamente de estos problemas, lo que sin lugar a dudas afecta el desarrollo de la disciplina. Así puede observarse, por ejemplo, en un conocido manual de Gian Franco Ricci, Principi di Diritto Processuale Generale, Giappichelli editore, 3ra. edic., Torino 2001, en donde se tratan aspectos generales concernientes al proceso civil, penal, administrativo, tributario, arbitral y en donde la referencia a la labor de la Corte Constitucional, a la cual se reconoce una labor jurisdiccional, no es objeto de mayor interés y quizá tampoco se entienda del todo (pp. 1-86).

\section{LA SITUACIÓN EN ALEMANIA. LA TESIS DEHÄBERLE}

A raíz de la creación del Tribunal Constitucional Federal (TCF) en la Ley Fundamental deBon en 1949, el problema del control deconstitucionalidad se replanteó en una Alemania distinta al periodo de entreguerras. El mismo Tribunal demoró en iniciar sus actividades y la misma legislación dela materia no fue ni muy extensa ni muy detallada, lo cual dejaba campo abierto al desarrollo jurisprudencial del Tribunal para hacer una labor creadora, que si bien es interesante, ha tenido algunas matizaciones con el tiempo, desenvolviéndosecon mesura.

De hecho, la incompleción dela Ley del Tribunal permitió a éste un adecuado manejo delassituaciones a las quetuvo queenfrentarse, en partepor la ausencia dela comunidad procesal, lo que retrasó el desarrol lo dela problemática, si lo comparamos, por ejemplo, con los debates surgidos en la comunidad jurídica italiana. Si bien esta libertad creadora tiene indudablemente sus límites en el resto del ordenamiento queactúa como un referente para evitar desbordes.

Dentro de ese contexto, quien primero utiliza el término "derecho procesal constitucional" es Peter Häberle, en un pionero estudio de 1973, que luego ahonda y desarrolla en otro ensayo muy difundido escrito en 1976: El derecho procesal constitucional como derecho constitucional concretizado frente a la judicatura del Tribunal Constitucional (ahora incorporado al libro de Häberle," Nueve ensayos constitucionales y una lección jubilar", PalestraA sociación Peruana de Derecho Constitucional, Lima 2004) y que ha contribuido a difundir en la comunidad jurídica alemana (cf. entre otros,Funktion und Bedeutung der Verfassungsgerichte in vergleichander 
Perspektive, en "EuGRZ" 2005, p. 686). Incluso su discípulo Klaus Engelman se ha encargado de desarrollar y afinar los planteos de Häberle (cf. K.Engelman, Prozessgrundsätzeim Verfassunsprozessrecht, Duncker und Humboldt, Berlín 1977, pp. 142-143).

La tesis de Häberle es rica y sugestiva y tiene un mar de fondo, pues está basada en la experiencia-inicial-del Tribunal Constitucional, que sobre la base de la Constitución y de la propia Ley Orgánica del Tribunal, ha hecho desarrollos de carácter procedimental en los procesos ll evados anteel Tribunal. Sobre esa base, Häberle extrae la conclusión de que el "derecho procesal constitucional" es una suerte de emanación del corpus constitucional , al cual sirve y del cual constituye su desarrollo, motivo por el cual cuando la Constitución, quetieneprincipios normativos seenfrenta con aspectos diversos dela real idad, seconcretan, se hacen posibles y hacen actuar la Constitución. De esta suerte, el "derecho procesal constitucional" no solo tiene peculiaridad, sino que tiene una cierta autonomía, entendiendo que si bien nace y se desarrolla a partir de la Constitución, tiene espacios que le garantizan un gran radio deacción. La tesis de Häberle, mantenida a través del tiempo, tiene sin embargo al gunos problemas no resueltos (cf. por ejemplo los comentarios de Joaquín BrageCamazano a su traducción deK.H esse-P.Häberle, Estudios sobre la jurisdicción constitucional, Biblioteca Porrúa de Derecho Procesal Constitucional, México 2005).

Esta tesis, sin embargo, no goza demayor aceptación en la doctrina, queno solo la critica (K. Stern) sino queopta por una solución más procesal (cf. Ernst BendaEckart Klein, Lehrbuch des Verfassungsprozessrechts, Müller Juristischer Verlag, Heidelberg 1991, pp. 12-16).

Lo importante, sin embargo, es que el término ha tenido entrada en el ámbito bibliográfico y académico al emán.Y así se cuenta con varios manuales con el título de "derecho procesal constitucional" de los que, al parecer, el que más uso extendido tienees el de Christian Pestal ozza (cf. Verfassungsprozessrecht, 3ra edición, C.H.Beck's Verlagsbuchhandlung, M ünchen 1991). Sin embargo, Pestall lozza no sehace cargo del problema del título ni dela disciplina ni tampoco desu fundamentación o ubicación teórica, sino quemás bien haceun tratamiento dela manera como funciona el Tribunal Constitucional Federal y los tribunales constitucionales de los länder así como delos procesos quesellevan anteellos, agregando un apéndice referido a la protección jurídica internacional. En su bibliografía cita otros textos de complemento desu libro-quesirvedebase a sus 
seminarios universitarios-tales como el ya citado de Benda/ Klein, Fleury, Hillgruber/ Goos, Sachs, etc.

Significativo es el pequeño manual de Michael Sachs (cf. Verfassungsprozessrecht, Verlag Recht und Wirtschaft, Heidelberg 2004) dedicado a la exposición de la dogmática alemana en este punto y que tan solo en la presentación que preside el texto intenta una definición del "derecho procesal constitucional", bastante imprecisa por lo demás (pp. 56). Más adel ante señala la principal bibliografía al emana sobreel tema (pp. 20-21).

Al igual queen Italia, el debate se da a nivel de los constitucional istas, si bien la aportación de Häberle, pese a no gozar de mayor predicamento hoy en día, es muy sugestiva (cf. Raúl Bocanegra Sierra, El valor delas sentencias del Tribunal Constitucional, IEAL, Madrid 1982, pp. 161-171 y Patricia Rodríguez-Patrón, La libertad del Tribunal Constitucional alemán en la configuración de su derecho procesal, en "Revista Española de Derecho Constitucional", mayoagosto de 2001, núm. 62).

\section{A MANERA DECONCLUSIÓN}

El rápido recorrido que he efectuado sobre la principal literatura existente no permite una conclusión definitiva, pues es probable que muchos datos se me hayan escapado por las limitaciones propias de toda investigación. Pero sin lugar a dudas es significativa y en todo caso representa básicamente lo que existe y es posible ubicar, más allá de márgenes de error o imprecisiones que siemprepueden presentarse.

Lo que interesa en primer lugar es fijar fechas en relación con la aparición de esta nueva disciplina que se llama "derecho procesal constitucional", que comprendeuna seriede principios einstrumentos de defensa dela Constitución. He dicho la disci plina y no la materia quela comprende, porque esta última se da desde hace más de doscientos años, si nos limitamos a lo cercano, pues remontando el curso dela historia podríamos ir más lejos, como en efecto lo han hecho al gunos estudiosos.

Pero el nombredela disciplina y la manera deenfocarla es relativamentereciente. Heseñal ado anteriormenteque debefijarseel año 1944 como el dela aparición del nomen iuris y no antes. Y si a eso añadimos el excurso teórico queapareció 
el año siguiente-1945-queda claro que esta es la fecha en que tal disciplina apareció. Esto sucedió en la A rgentina, por obra de un destacado procesalista español residente en aquel país en forzado exilio: Niceto Alcalá-Zamora y Castillo. Y lo reiteró en M éxico dos años después.

Pero lo llamativo es queel nombre aparecido en la Argentina, no tuvo eco en ese país y tampoco de inmediato en el siguiente país al cual arribó en exilio: M éxico. Sino que demoró mucho en usarse y más aun en tener un desarrollo que ha ido creciendo con los años, pero sin que ello haya contribuido a crear una generalizada aceptación ni menos aun que queden fijados sus temas principales.

Haciendo un esquema cronológico de esta recepción por países, tendríamos la siguiente lista que debe considerarse válida, en tanto no sea objeto de rectificación:

a. 1944-1945. Niceto A lcalá-Zamora y Castillo(Argentina)

b. 1947. Niceto A Icalá-Zamora y Castillo(M éxico)

c. 1948. EduardoJ. Couture (Uruguay)

d. 1955. Héctor Fix-Zamudio (M éxico)

e. 1958. JoséFrederico Marques (Brasil)

f. 1959. Renzo Provinciali (Italia)

g. 1960. Fernando Álvarez Tabio (Cuba)

h. 1971. Domingo García Belaunde(Perú)

i. 1973. Peter Häberle (A lemania)

j. 1977. HumbertoJ. La Roche(Venezuela)

k. 1979. JoséA Imagro N osete (España)

1. 1979. N éstor P. Sagüés (A rgentina)

m. 1988. Hugo Pereira A nabalón-H umberto N ogueira A Icalá (Chile)

n. 1993. Sebastián Rodríguez Robles (Panamá)

o. 1994. Ernesto Rey Cantor (Colombia)

p. 1995. Rubén Hernández Valle (Costa Rica)

q. 1998. José Decker Morales (Bolivia)

r. 1998. Louis Favoreu (Francia)

s. 1999. Ivan Escobar Fornos (Nicaragua)

t. 2002. Rafael Luciano Pichardo-José Hernández Machado (República Dominicana)

u. 2005. Pablo Pérez Tremps (Ecuador) 
Como se puede apreciar, el concepto "derecho procesal constitucional" aparece en la Argentina y luego en M éxico, esto es, dos importantes comunidades académicas latinoamericanas, y que son las que dan los primeros pasos. Pero luego vino su desarrollo, quetambién seda en nuestra región.

Europa aparece prácticamenteal margen deestos empeños.....Tan solo Italia se muestra interesada en un primer momento por el problema teórico, pero pasados los años se desentiende del tema. Con menor intensidad se inicia el debate en A lemania, pero en Austria, madre del model o concentrado y hogar intel ectual de Kelsen, se desconoce el término. El mismo Kelsen lo ignoró. Y lo mismo podría decirse de Francia, y en cierto sentido de España.

El primer problema es pues, con el nombre. Pues incluso quienes lo usan, devez en cuando y quizá para ser mejor entendidos o si mplemente para estar en una onda editorial o por comodidad léxica, usan rótulos tradicionales, en especial el de "justicia constitucional".

El segundo problema es sobre su configuración jurídica. La tendencia es a considerarlo como algo procesal, perteneciente al Derecho Procesal, pero no todos concuerdan con ello. Hay tesis quelo niegan, como la quesostienequeel "derecho procesal constitucional" o la "justicia o jurisdicción constitucional" no es otra cosa queuna parte del Derecho Constitucional, como concretización de éste o como una de sus emanaciones. Esta tesis, que nos recuerda las polémicas de hace más de ciento cincuenta años, nos podría llevar al absurdo de sostener que el Derecho Procesal Civil, por poner un ejemplo, sea algo así como "derecho civil concretizado" y considerarlo como una prolongación de éste. Para estos enfoques, el "derecho procesal" no existiría, y de existir, no debería ser aplicado ni menos usarlo para el desarrollo delas defensas de tipo constitucional. Y claro, si esto es así... ¿que criterios o procedimientos utilizamos? O recurrimos a la teoría procesal, con solera de más de un siglo. O inventamos otra quela sustituya.

En fin, otra tesis más sugestiva, es la de la mixtura. Según este planteo, el "derecho procesal constitucional" es una disciplina mixta porque parte de ambas, el Derecho Constitucional y el Derecho Procesal y no puededesligarsedeninguna de ellas por cuanto guardan una mutua dependencia. Pero podríamos preguntarnos con ese mismo criterio si no es cierto que en este supuesto el "derecho procesal civil" sería también una disciplina mixta. 
Una postura en cierto sentido nueva, es la surgida en el Brasil desdeun principio, y que gran parte de la doctrina en ese país la acepta y más aun la difunde. Y es ésta: el "derecho procesal constitucional" no es algo independiente y que tenga autonomía, sino que es un simple condensado metodológico, de carácter propedéutico, quesirvepara explicarnos las demás ramas del proceso (en especial el proceso civil y el penal). Con lo cual el "derecho procesal constitucional" desaparece y forma parte de la doctrina procesal o de la teoría del proceso y es usado por cualquier procesalista en cual esquiera de sus especialidades y como paso previo al estudio decual esquiera deellas. Pero curiosamenteesto envuelve también una contradicción. Los queaceptan esteenfoque, no niegan la existencia deprocesos constitucionalesen el Brasil-como son el H abeas Corpus, el Mandato de Seguridad, etc.- ante lo cual cabe la pregunta ¿dónde ubicamos a estos procesos...? ¿será el Habeas Corpus un proceso penal y el Mandato deSeguridad un proceso civil...? Lo cual sería muy peculiar, porqueel proceso civil tiene por objeto hacer efectivo el ordenamiento civil y no la Constitución....

Otro punto que cabe agregar es queincluso en países que utilizan ampliamente el término "justicia constitucional" no se niega que ante los órganos competentes accionamos o ponemos en movimiento "procesos constitucionales", que básicamente son deorden contencioso. En Ital ia esto es clarísimo desdela obra magistral deZagrebel sky hasta las aportaciones periódicas de Roberto Romboli y el grupo de Pisa, que aceptan la existencia de procesos constitucionales. La pregunta sería entonces ¿en dónde los ubicamos...?

El "derecho procesal constitucional" afronta pues, serios problemas. El primero es el nombremismo, el segundo es su ubicación o configuración teórica o como quieren algunos, la naturaleza de la disciplina. Y finalmente-si bien no necesariamentelo último-los temas que debe tratar y que son partedesu objeto.

Mearriesgo a pensar que los que primero seinteresaron en el tema lo hicieron por intuición y un poco al azar. Dehecho, en los Estados Unidos estetópico no existe, porque el "judicial review" no es un proceso, sino una técnica de control de la supremacía constitucional, que es distinto. Y que se da al interior de cualquier proceso. Y los pioneros del model o concentrado o europeo, tampoco eran duchos en Derecho Procesal y pienso que ni se percibieron de ello (en el caso deKelsen, esto es fácilmentecomprobable).

A lo anterior se añade que, salvo notables y esporádicas excepciones, los procesalistas no se han hecho cargo del tópico. En rigor, parece que no les 
interesa, como se acredita en los temarios de los congresos nacionales e internacionales de Derecho Procesal, en dondeel tema no aparece, o si aparece lo haceen forma rezagada, sin contar con el hecho dequeno goza dela preferencia delos asistentes. Se trata de al go que no existe o que en todo caso es marginal.

Pero en el lado del os constitucionalistas la cosa no va por mejor camino. Sehan hecho cargo de la problemática, con más entusiasmo que conocimientos. Y si están de acuerdo en que se trata de situaciones que deben ser remediadas o despejadas por una autoridad competente-debidamente premunida por el Estado-y que hay que seguir determinados pasos ante ella, es claro que estos pasos o seguimientos deben tener un orden que debe pre-existir a los acontecimientos y queconstituyen las reglas del juego. Y aquí tenemos solo dos posibilidades: o utilizamos el proceso creado por la doctrina y la legislación positivas y quefunciona satisfactoriamenteen otros sectores del mundo jurídico. O simplementeinventamos al go distinto, no sabemos con quesuerte.

Pero lo que más llama la atención en estos casos, es que cuando los constitucional istas analizan y estudian estos temas, probablementecon mucho talento y perspicacia, lo hacen ayunos de conocimiento procesal, y en consecuencia el esfuerzo que realizan se vuelve descomunal y de repente no rindetodos susfrutos. Creo, pues, queuna sugerencia interesantesería estudiar en serio la teoría del Derecho Procesal para ver por donde va y en quenos puede servir. Y esto es aconsejable más aun hoy en día, en donde las especialidades entre los juristas crean entre ellos verdaderos compartimientos estancos, que impiden el diálogo entresectores vecinos o complementarios (y lo mismo podría decirse de los procesalistas, que deberían mostrar más interés en conocer el Derecho Constitucional).

Por supuesto, no son estos los únicos factores que han dificultado el desarrollo y sobre todo el orden previo que debe fijarse en toda rama del Derecho y en especial en el Derecho Procesal Constitucional. Pero algo se habrá avanzando si contribuimos a solucionarlo.

M ientras tanto, el hecho de comprobar la forma tan extensa como el nombrese ha extendido y se discute-sobre todo en la A mérica Latina-es síntoma de su vitalidad y de su existencia. Pues como decía Pascal, no lo buscaríamos si es queno lo hubiésemos encontrado. 